\title{
Delta-opioid receptor (DOR) activation prolongs respiratory motor output during oxygen-glucose deprivation (OGD) in neonatal rat spinal cord in vitro
}

\author{
Sara M. F. Turner and Stephen M. Johnson \\ Department of Comparative Biosciences, School of Veterinary Medicine, University of Wisconsin, \\ Madison, Wisconsin 53706
}

\section{Abstract}

Delta opioid receptor (DOR) activation protects the adult mammalian brain during oxygen-glucose deprivation (OGD), but it is not known whether neonatal spinal motor circuits are also protected. Also, it is unclear whether the timing of spinal DOR activation relative to spinal OGD is important for neuroprotection. Thus, a split-bath in vitro neonatal rat brainstem/spinal cord preparation was used to record spontaneous respiratory motor output from cervical (C4-C5) and thoracic (T5-T6) ventral spinal roots while exposing only the spinal cord to OGD solution $(0 \mathrm{mM}$ glucose, bubbled with 95\% $\mathrm{N}_{2} / 5 \% \mathrm{CO}_{2}$ ) or DOR agonist drugs (DADLE, DPDPE). Spinal OGD solution application caused respiratory motor output frequency and amplitude to decrease until all activity was abolished (i.e., end-point times) after $25.9 \pm 1.4 \mathrm{~min}$ (cervical) and $25.2 \pm 1.4 \mathrm{~min}$ (thoracic). Spinal DOR activation via DPDPE $(1.0 \mu \mathrm{M})$ prior-to and during spinal OGD increased cervical and thoracic end-point times to 35-48 min. Spinal DADLE or DPDPE $(1.0 \mu \mathrm{M})$ application 15 min following spinal OGD onset increased cervical and thoracic end-point times to $36-45 \mathrm{~min}$. Brief spinal DPDPE $(1.0 \mu \mathrm{M})$ application for $10 \mathrm{~min}$ at $25 \mathrm{~min}$ before spinal OGD onset increased cervical and thoracic end-point times to 41-46 min. Overall, the selective DOR agonist, DPDPE, was more effective at increasing end-point times than DADLE. Naltrindole (DOR antagonist; 10 $\mu \mathrm{M})$ pretreatment blocked DPDPE-dependent increase in end-point times, suggesting that DOR activation was required. Spinal naloxone $(1.0 \mu \mathrm{M})$ application before and during spinal OGD also increased end-point times to 31-33 min, but end-point times were not altered by MOR activation or DOR activation/MOR blockade, indicating that there are complex interactions between OGD and opioid signaling pathways. These data suggest DOR activation before, during, and after spinal OGD protects central motor networks and may provide neuroprotection during unpredictable perinatal ischemic events.

\section{Keywords}

ischemia; neonatal; neuroprotection; delta opioid receptor; respiratory; spinal

\footnotetext{
(C) 2011 IBRO. Published by Elsevier Ltd. All rights reserved.

Corresponding Author: Stephen M. Johnson, M.D., Ph.D., Assistant Professor, Department of Comparative Biosciences, School of Veterinary Medicine, University of Wisconsin, 2015 Linden Drive, Madison, Wisconsin 53706, Phone: (608)261-1104, Fax: (608)263-3926, johnsons@svm.vetmed.wisc.edu.

Publisher's Disclaimer: This is a PDF file of an unedited manuscript that has been accepted for publication. As a service to our customers we are providing this early version of the manuscript. The manuscript will undergo copyediting, typesetting, and review of the resulting proof before it is published in its final citable form. Please note that during the production process errors may be discovered which could affect the content, and all legal disclaimers that apply to the journal pertain.
} 
Oxygen-glucose deprivation (OGD) initiates a deleterious cascade of neuronal depolarization, glutamate release, $\mathrm{Na}^{+}$and $\mathrm{Ca}^{2+}$ ion influx, acute excitotoxicity, and longlasting neuronal damage (Pugliese et al., 2003; Bickler, 2004). Perinatal OGD affects 1 of 2300-5000 live births due to stroke, acute circulatory collapse, placental insufficiency, or cardiorespiratory failure (Badr and Purdy, 2006; Nelson, 2007; Rennie et al., 2007). Perinatal OGD can also cause motor system disorders such as seizures, cerebral palsy, hypotonia, and apneas (Volpe, 2001; Badr and Purdy, 2006; Sotero de Menezes and Shaw, 2006; Nelson, 2007). Over 50\% of full-term children with perinatal hypoxic-ischemic encephalopathy have mild to significantly delayed motor ability (van Schie et al., 2007). Since no successful treatments exist (Badr and Purdy, 2006), novel strategies must be developed to protect CNS motor networks before, during and after perinatal OGD.

One strategy for providing neuroprotection against perinatal OGD is to apply principles learned from naturally hypoxia- and ischemia-resistant species (Borlongan et al., 2004). Delta opioid receptors (DOR) are endogenous, evolutionarily conserved (Xia and Haddad, 2001), and activated during physiological stress (Hwang et al., 1986). DOR activation is a potential mechanism for hypoxia/ischemia resistance because hypoxia-resistant red-eared slider turtles have more central DOR receptors compared to rats (Xia and Haddad, 2001). Also, endogenous DOR activation may contribute to neuroprotection in hibernating mammals during torpor when blood flow to the brain is severely reduced (Drew et al., 2001, 2007). Thus, DOR activation in ischemia-sensitive mammals may be a powerful mechanism for inducing neuroprotection.

Accordingly, in cultured cortical or hippocampal neurons, DOR activation prior to excitotoxic glutamate application attenuates neuronal damage and death (Zhang et al., 2006; Zhao et al., 2006b). With respect to central motor networks, spinal OGD rapidly impairs motor function in swine in vivo (Lee et al., 2008) and in rats in vitro (Jha et al., 2003; Deshpande and Jha, 2004). However, intrathecal DOR agonist administration 9 min prior to spinal cord ischemia improves hind limb motor performance and reduces histological damage in spinal ventral horn (Horiuchi et al., 2004). Although DOR activation provides neuroprotection in mature mammals, it is not known whether DOR activation protects neonatal spinal motor networks. Also, it's important to know whether DOR-dependent neuroprotection depends on the timing of DOR drug administration with respect to OGD onset, since perinatal ischemia is clinically unpredictable.

To address these questions, spontaneous respiratory motor output from cervical and thoracic ventral spinal rootlets was recorded in neonatal rat brainstem-spinal cord preparations in vitro. We tested whether respiratory spinal motor output was prolonged by the following conditions: 1) sustained spinal DOR activation 10 min prior-to and during spinal OGD, 2) spinal DOR activation at 10 min post-spinal OGD onset, and 3) brief spinal DOR activation for $10 \mathrm{~min}$ at $25 \mathrm{~min}$ before spinal OGD onset. This is the first study to illustrate the protective effects of DOR activation before, during, and after OGD in a neonatal spinal respiratory motor circuit. Preliminary results were published in abstract form (Freiberg et al., 2008a,b).

\subsection{Experimental Procedures}

\subsection{Brainstem-spinal cord preparations}

The University of Wisconsin Institutional Animal Care and Use Committee approved all experimental procedures and all experiments conformed to International Guiding Principles for Biomedical Research Involving Animals as established by the Council for International 
Organizations of Medical Sciences. Neonatal (P1-P3) Sprague-Dawley rats ( $\mathrm{n}=138$, Charles River, Wilmington, MA, USA) of either sex were anesthetized with 5\% isoflurane $\left(\mathrm{O}_{2}\right.$ balance) before being decerebrated. The remaining tissue was placed in ice-cold artificial cerebrospinal fluid (aCSF), composed of (in $\mathrm{mM}$ ): $120 \mathrm{NaCl}, 26 \mathrm{NaHCO}_{3}, 20$ glucose, 2 $\mathrm{MgSO}_{4}, 1 \mathrm{CaCl}_{2}, 3 \mathrm{KCl}$, and $1.25 \mathrm{Na}_{2} \mathrm{HPO}_{4}$. The brainstem and spinal cord from the pontomedullary border to thoracic spinal segment $\mathrm{T} 12$ was removed in ice-cold aCSF and pinned down ventral side up in a standard recording chamber. A plastic and petroleum jelly barrier at $\mathrm{C} 1$ separated the chamber into a brainstem compartment (volume $=4.5 \mathrm{ml}$ ) and spinal compartment (volume $=8.5 \mathrm{ml}$ ) (Fig. 1A). The brainstem and spinal compartments were continuously bathed with oxygenated aCSF solution $\left(26^{\circ} \mathrm{C}\right.$, aerated with $5 \% \mathrm{CO}_{2}$ and $95 \% \mathrm{O}_{2}, \mathrm{pH}=7.4$ ) at a flow rate of $7-8 \mathrm{ml} / \mathrm{min}$ in each compartment. During each experiment the brainstem compartment was always bathed with oxygenated aCSF. To expose the spinal cord to OGD, the spinal compartment was bathed with OGD solution, which was aCSF solution with $20 \mathrm{mM}$ sucrose substituted for $20 \mathrm{mM}$ glucose (aerated with $5 \% \mathrm{CO}_{2}$ and $95 \% \mathrm{~N}_{2}, \mathrm{pH}=7.4$ ).

\subsection{Electrophysiological recordings of spinal respiratory motor output}

Spontaneously produced respiratory motor output was recorded by attaching glass suction electrodes to cervical $\left(\mathrm{C}_{3}-\mathrm{C}_{5}\right.$; phrenic motoneurons) and thoracic $\left(\mathrm{T}_{4}-\mathrm{T}_{6}\right.$; intercostal motoneurons) nerve roots. Signals were acquired at $50 \mathrm{~Hz}$, amplified $(10,000 \mathrm{x})$ and bandpass filtered $(0.1-500 \mathrm{~Hz}$ ) using a differential AC amplifier (model 1700, A-M Systems, Everett, WA, USA) before being rectified and integrated (time constant $=50 \mathrm{~ms}$ ) using a moving averager (MA-821/RSP, CWE, Inc., Ardmore, PA, USA; Fig. 1B). Data were collected using Axoscope hardware and software (Molecular Devices, Sunnyvale, CA, USA).

Brainstem-spinal cord preparations were allowed to equilibrate for 10-40 min before recording baseline data for $5 \mathrm{~min}$. If respiratory spinal motor output decreased by $>20 \%$ before spinal OGD application (without drug application), the experimental results were discarded. For all protocols with spinal OGD application, recordings were continued for $>20$ min after all spontaneous respiratory spinal motor activity was abolished. At the end of every experiment, the integrity of the barrier at spinal segment $\mathrm{C} 1$ was checked by injecting Chicago Blue dye into the brainstem compartment. If any dye flowed into the spinal compartment, the experiment results were discarded.

\subsection{Oxygen measurements in the spinal compartment}

Oxygen levels $\left(\mathrm{PO}_{2}\right)$ in the spinal compartment were measured with an oxygen electrode (ISO-OXY-2, World Precision Instruments, Sarasota, FL, USA) placed 1-2 mm lateral to the thoracic spinal cord at T5-T6 (contralateral to the suction electrode). Signals from the oxygen electrode were processed by an Apollo 4000 amplifier (World Precision Instruments) and recorded using Axoscope software. For calibration, the oxygen electrode was placed into the oxygenated aCSF and the OGD solution reservoirs for 5-10 min each prior to the experiment. The voltages measured in the reservoirs were set to be equal to the average reservoir $\mathrm{PO}_{2}$ that was measured six different times with $1.0 \mathrm{ml}$ samples withdrawn from the reservoir and injected into a blood-gas analyzer (ABL800 Flex, Radiometer America, Westlake, OH, USA). The $\mathrm{PO}_{2}$ values were $593 \pm 14 \mathrm{~mm} \mathrm{Hg}$ and $57 \pm 4 \mathrm{~mm} \mathrm{Hg}$ in the oxygenated aCSF and OGD solution reservoirs, respectively. The bath was open to the air so that the $\mathrm{PO}_{2}$ in the spinal compartment solution was larger than the value in the OGD solution reservoir (see Fig. 2F). 


\subsection{Experimental drugs}

All drugs were obtained from Sigma-Aldrich, Inc. (St. Louis, MO, USA). DOR agonists included DPDPE ([D-Pen $\left.{ }^{2,5}\right]$-Enkephalin hydrate; DOR agonist), DADLE ([D-Ala2, DLeu5]-enkephalin acetate salt; DOR agonist); DAMGO ([D-Ala ${ }^{2}, \mathrm{~N}-\mathrm{MePhe}^{4}$, Gly-ol]enkephalin; mu-opioid [MOR] agonist) antagonists included naloxone (opioid receptor antagonist), naltrindole (DOR antagonist) and 3 $\beta$-naltrexol (MOR antagonist).

\subsection{Data Analysis}

Voltage traces of spinal respiratory motor output or "bursts" were analyzed using Clampfit software (Molecular Devices, Sunnyvale, CA, USA). Respiratory motor burst amplitude was measured at the peak of integrated nerve discharge and normalized to baseline. Thoracic burst frequency was measured as the number of thoracic respiratory bursts/min and graphed as percent change from baseline. Data were averaged into 5-min bins such that the 30-min time-point represents the averaged data from 25.0-29.9 min. Data were reported as mean \pm SEM. One-way and two-way ANOVA's were performed with post-hoc comparisons using the Student-Newman-Keuls test in Sigma Stat software (Jandel Scientific Software, San Rafael, CA, USA). If normality or equal variance assumptions failed, data were transformed using the natural log or arcsine transforms (e.g., ln transform was used for the cervical doseresponse DADLE endpoints, thoracic dose-response DPDPE endpoints, and thoracic DADLE post-OGD onset endpoints; Arcsin square root was used for cervical and thoracic sustained DPDPE amplitude). $\mathrm{P}<0.05$ was considered statistically significant.

\subsection{Results}

\subsection{Spinal OGD abolishes spinal respiratory motor output}

For time control experiments $(n=8)$ in which the brainstem and spinal cord compartments were continuously bathed in aCSF solution, cervical burst amplitude decreased slowly over time to $75 \pm 6 \%$ of baseline after $120 \mathrm{~min}$ ( $\mathrm{p}<0.05$ for $65-120 \mathrm{~min}$; one-way RM ANOVA; Fig. 2B). In contrast, thoracic burst amplitude was unaltered over time ( $\mathrm{p}=0.95$; one-way RM ANOVA; Fig. 2C). Thoracic burst frequency was $94 \pm 14 \%$ of baseline after 120 min ( $\mathrm{p}=0.93$; one-way RM ANOVA; Fig. 2D). Thus, brainstem-spinal cord preparations produced quantifiable, spontaneous respiratory motor output for 120 min with cervical burst amplitude decreasing gradually over time.

In separate experiments ( $\mathrm{n}=11)$, baseline data were recorded ( $5 \mathrm{~min}$ ), aCSF solution was spinally applied (10 min), and then OGD solution was spinally applied until all activity was abolished (Fig. 2A). Cervical and thoracic burst amplitudes were decreased compared to time controls at 20-30 min post-OGD onset ( $<<0.001$; Figs. 2C, 2D). To test whether spinal burst area was correlated with burst amplitude, area was graphed versus amplitude using the 5-min bin data from each OGD experiment (this permits a wide range of data to be compared). Cervical and thoracic burst areas were tightly correlated with their respective amplitudes (cervical: slope $=1.00, \mathrm{r}^{2}=0.862$; thoracic: slope $=0.95, \mathrm{r}^{2}=0.838$ ). Cervical and thoracic motor activity was abolished at $25.9 \pm 1.4 \mathrm{~min}$ (range $=17.6-33.0 \mathrm{~min} ; \mathrm{p}=0.027$ for drug effect) and 25.2 $\pm 1.4 \mathrm{~min}$ (range $=17.3-32.6 \mathrm{~min} ; \mathrm{p}<0.001$ for drug effect), respectively (Figs. 4A, 4B). Thoracic burst frequency (baseline $=4.2 \pm 1.2$ bursts $/ \mathrm{min}$ ) was decreased compared to time controls at 30-35 min post-OGD onset ( $\mathrm{p}=0.04$ for drug effect; Fig. $2 \mathrm{E}$ ). Spinal compartment $\mathrm{PO}_{2}$ was $458 \pm 17 \mathrm{~mm} \mathrm{Hg}$ during baseline, decreased to $165 \pm 22 \mathrm{~mm}$ $\mathrm{Hg}$ after $10 \mathrm{~min}$ of spinal OGD, and was $98 \pm 11 \mathrm{~mm} \mathrm{Hg}$ after $30 \mathrm{~min}$ of spinal OGD (Fig. $2 \mathrm{~F})$.

To test whether OGD altered spinal burst shape, the time from burst onset to the time of burst peak was divided by burst duration to calculate percent time to the peak. In general, 
the percent time to the peak during baseline was less than $20 \%$ (i.e., rapid onset and decrementing; Fig. 2B). For the OGD experiments, percent time to peak during baseline was $14 \pm 6 \%$ (cervical) and $12 \pm 4 \%$ (thoracic). During the last 20 spinal bursts, cervical percent time to peak increased to $29 \pm 9 \%$ ( $\mathrm{p}=0.004$ ), while thoracic percent time to peak remained unchanged at $19 \pm 5(\mathrm{p}=0.11)$. Thus, spinal OGD application did not dramatically alter spinal burst shape.

\subsection{Spinal DOR activation prior-to and during spinal OGD prolongs respiratory motor output}

DOR agonists (DADLE or DPDPE) were applied to the spinal cord for 10 min prior-to and during spinal OGD until spinal motor output was abolished (Fig. 3A). Since mean baseline thoracic burst frequencies were similar for OGD- and DOR agonist-treated preparations (3.4-4.5 bursts/min; $p>0.38)$, frequency data were graphed as percent baseline frequency. DADLE $(0.1 \mu \mathrm{M} ; \mathrm{n}=3)$ application did not alter the OGD-induced frequency decrease (Fig. $3 \mathrm{~A})$. DADLE $(1.0 \mu \mathrm{M} ; \mathrm{n}=7)$ increased burst frequency compared to OGD at 30-55 min postOGD onset $(\mathrm{p}<0.002)$ with $4 / 7$ preparations active at 50 min post-OGD onset (Fig. 3A). DADLE $(10 \mu \mathrm{M} ; \mathrm{n}=5)$ increased burst frequency at 30-50 min post-OGD onset in $3 / 5$ preparations (p<0.04; Fig. 3A). In $2 / 5$ preparations, DADLE $(10 \mu \mathrm{M})$ application abolished rhythmic activity before OGD onset (data excluded from Fig. 3A).

DPDPE $(0.1 \mu \mathrm{M} ; \mathrm{n}=5$ or $10 \mu \mathrm{M} ; \mathrm{n}=3)$ did not alter the OGD-dependent frequency decrease except for the 30-min time point for $0.1 \mu \mathrm{M}$ DPDPE (p<0.003; Fig. 3B). DPDPE $(1.0 \mu \mathrm{M}$; $\mathrm{n}=8$ ) increased burst frequency compared to OGD data at 30-55, 65, and 75 min post-OGD onset with $3 / 8$ preparations still active at 50 min post-OGD onset $(\mathrm{p}=0.015$ for drug effect; Fig. 3B).

When respiratory motor output was quantified as end-point times (i.e., time from OGD onset to time when spinal nerve motor activity was abolished) in OGD experiments, DADLE ( 0.1 $\mu \mathrm{M})$ did not alter cervical $(\mathrm{p}=0.97)$ and thoracic $(\mathrm{p}=0.86)$ end-point times (Figs. 4A, 4B). DADLE $(1.0 \mu \mathrm{M})$ did not alter cervical end-point times (34.0 $\pm 4.4 \mathrm{~min} ; \mathrm{p}=0.127$; Fig. $4 \mathrm{~A})$, but increased thoracic end-point times to $48.5 \pm 5.3 \mathrm{~min}$ (range $=27.7-67.0 \mathrm{~min} ; \mathrm{p}<0.001$; Fig. 4B). DADLE (10 $\mu \mathrm{M}$; data from $3 / 5$ preparations) prolonged cervical and thoracic endpoint times to $55.1 \pm 12.8 \mathrm{~min}$ (range $=32.3-76.7 \mathrm{~min}$; $\mathrm{p}=0.004$; Fig. $4 \mathrm{~A}$ ) and $58.5 \pm 9.0 \mathrm{~min}$ (range $=49.3-76.5 \mathrm{~min} ; \mathrm{p}<0.001$; Fig. 4B), respectively. DPDPE at $0.1 \mu \mathrm{M}$ and $10 \mu \mathrm{M}$ did not prolong cervical or thoracic end-point times ( $>0.42$; Figs. 4A, 4B). However, DPDPE $(1.0 \mu \mathrm{M})$ prolonged cervical end-point times to $35.9 \pm 3.9 \mathrm{~min}$ (range $=22.7-52.0 \mathrm{~min}$; $\mathrm{p}=0.035)$ and thoracic end-point times to $48.9 \pm 9.7 \mathrm{~min}($ range $=22.6-103.9 \mathrm{~min} ; \mathrm{p}=0.007)$ (Figs. 4A, 4B). These data show that DADLE was ineffective at $0.1 \mu \mathrm{M}$, and DPDPE was ineffective at 0.1 and $10 \mu \mathrm{M}$. DADLE at $10 \mu \mathrm{M}$ increased end-point times, but tended to abolish respiratory rhythm. Thus, amplitude data are shown only for 1.0 $\mu \mathrm{M}$ DADLE and DPDPE (Figs. 4C, 4D) and all subsequent experiments were performed at $1.0 \mu \mathrm{M}$.

With respect to cervical burst amplitude, DADLE $(1.0 \mu \mathrm{M})$ had no effects, but DPDPE (1.0 $\mu \mathrm{M})$ attenuated OGD-induced amplitude decrease at $15-30 \mathrm{~min}(\mathrm{p}=0.016$ for drug effect; Fig. 4C). For thoracic motor output, DADLE increased burst amplitude at 25-30 min $(\mathrm{p}<0.05$; Fig. 4D), while DPDPE $(1.0 \mu \mathrm{M})$ increased burst amplitude at 20-30 min postOGD onset ( $\mathrm{p}=0.019$ for drug effect; Fig. 4D). Statistical comparisons were only performed during 5-30 min post-OGD onset because 15/17 preparations exposed to OGD alone were silent after $30 \mathrm{~min}$. 


\subsection{Spinal DOR activation following spinal OGD onset prolongs respiratory motor output}

DADLE $(1.0 \mu \mathrm{M}, \mathrm{n}=7)$ or DPDPE $(1.0 \mu \mathrm{M}, \mathrm{n}=7)$ was added to the spinal compartment 15 min following spinal OGD solution application. DADLE increased burst frequency (baseline $=4.0 \pm 0.49$ bursts $/ \mathrm{min}$ ) compared to OGD at $25-55 \mathrm{~min}$ post $-\mathrm{OGD}$ onset $(\mathrm{p}=0.011$ for drug effect; Fig. 5 A). DADLE increased cervical and thoracic end-point times to $40.7 \pm 6.3 \mathrm{~min}$ (range=23.6-65.9 min; $\mathrm{p}=0.008)$ and 45.3 $\pm 7.1 \mathrm{~min}($ range=26.1-73.1 $\mathrm{min} ; \mathrm{p}<0.001)$, respectively (Figs. 5C, 5D). DADLE did not alter the OGD-induced decrease in cervical and thoracic burst amplitudes (Figs. 5E, 5F). DPDPE increased thoracic burst frequency (baseline $=4.4 \pm 0.62$ bursts $/ \mathrm{min}$ ) at $25-50 \mathrm{~min}$ post-OGD onset ( $<<0.001$ for drug effect; Fig. 5B) and increased cervical and thoracic end-point times to $36.2 \pm 2.0$ min (range $=23.6-$ $65.9 \mathrm{~min} ; \mathrm{p}<0.001$ ) and $41.4 \pm 3.6 \mathrm{~min}$ (range $=26.1-73.1 \mathrm{~min} ; \mathrm{p}<0.001$ ), respectively (Figs. $5 \mathrm{C}, 5 \mathrm{D})$. DPDPE increased cervical burst amplitude at 25-30 min and thoracic burst amplitude at 20-25 min post-OGD onset (Figs. 5E, 5F).

\subsection{Brief spinal DOR activation before OGD prolongs spinal respiratory motor output}

To test whether DOR activation induces long-lasting effects, DADLE $(1.0 \mu \mathrm{M} ; \mathrm{n}=9)$ or DPDPE ( $1.0 \mu \mathrm{M} ; \mathrm{n}=6)$ was applied to the spinal cord for $10 \mathrm{~min}$, followed by aCSF solution for $25 \mathrm{~min}$, and then OGD solution until $20 \mathrm{~min}$ after motor output was abolished (Figs. 6A, 6B). To control for potential time-dependent effects on respiratory motor output, separate OGD control experiments $(n=6)$ were performed in which OGD solution was applied to the spinal cord after a 40-min baseline period. Similar to the OGD experiments in Fig. 2, OGD abolished cervical and thoracic bursts at $24.3 \pm 1.7 \mathrm{~min}$ (range=20.3-31.9 min) and $26.8 \pm$ $1.8 \mathrm{~min}$ (range=20.9-32.7 min), respectively (Figs. 6C, 6D).

DADLE did not alter OGD-induced changes in thoracic burst frequency (baseline $=4.5 \pm$ 0.33 bursts/min; Fig. $6 \mathrm{~A}$ ) or thoracic end-point times ( $34.6 \pm 4.9 \mathrm{~min} ; \mathrm{p}=0.23$; Fig. $6 \mathrm{D})$, but increased cervical end-point times to $32.0 \pm 2.0 \mathrm{~min}$ (range $=23.5-41.2 \mathrm{~min} ; \mathrm{p}=0.018$; Fig. 6C). DADLE did not alter spinal burst amplitude (Figs. 6E, 6F). DPDPE increased thoracic burst frequency (baseline $=4.3 \pm 0.59$ bursts $/ \mathrm{min}$ ) at $25-45$ and $60 \mathrm{~min}$ post-OGD onset $(\mathrm{p}=0.015$ for drug effect; Fig. 6B) and increased cervical and thoracic end-point times to $41.0 \pm 2.5 \mathrm{~min}(\mathrm{range}=31.3-49.6 \mathrm{~min})$ and $46.0 \pm 3.5 \mathrm{~min}($ range $=39.4-61.8 \mathrm{~min})$, respectively ( $\mathrm{p}<0.001$ for both; Figs. 6C, 6D). DPDPE did not alter spinal burst amplitude (p>0.64; Figs. 6E, 6F).

\subsection{DPDPE-dependent neuroprotection requires spinal DOR activation}

To test whether DPDPE effects were due to DOR activation, naltrindole (10 $\mu \mathrm{M}$; selective DOR antagonist) was continuously applied to the spinal cord $10 \mathrm{~min}$ prior to initiating a spinal DPDPE $(1.0 \mu \mathrm{M})$ and OGD experiment similar to that shown in Fig. 3B $(n=5)$. Naltrindole abolished the DPDPE-dependent prolongation of spinal respiratory motor output with cervical and thoracic end-point times of $24.5 \pm 4.6$ and $26.2 \pm 3.6 \mathrm{~min}$, respectively (p>0.72; Figs. 7A, 7B). To test whether ongoing endogenous spinal DOR activation in neonatal rat brainstem-spinal cord preparations is neuroprotective, naltrindole $(10 \mu \mathrm{M})$ was applied to the spinal cord prior-to and during spinal OGD $(\mathrm{n}=7)$. Under these conditions, there were no differences in end-point times compared to OGD for cervical $(20.8 \pm 3.8 \mathrm{~min}$; $\mathrm{p}=0.17)$ or thoracic $(22.6 \pm 4.2 \mathrm{~min} ; \mathrm{p}=0.49)$ respiratory motor output (Figs. 7A, 7B).

\subsection{Role of endogenous spinal opioid receptors during spinal OGD}

To test whether general blockade of spinal opioid receptors alters the response to spinal OGD, naloxone $(1.0 \mu \mathrm{M}$; broad spectrum opioid receptor antagonist; $\mathrm{n}=8)$ was applied 10 min prior-to and during spinal OGD (Fig. 8A). Naloxone increased thoracic burst frequency (baseline $=4.5 \pm 0.8$ bursts $/ \mathrm{min}$ ) at 30-35 min post-OGD onset ( $<<0.001$; Fig. $8 \mathrm{~A})$. 
Naloxone also prolonged cervical and thoracic motor end-point times to $31.7 \pm 1.3 \mathrm{~min}$ (range=25.6-36.9 $\mathrm{min} ; \mathrm{p}=0.008)$ and 33.9 $\pm 1.6 \mathrm{~min}($ range $=30.1-41.5 \mathrm{~min} ; \mathrm{p}<0.001)$, respectively (Fig. 8B). Naloxone application did not alter cervical or thoracic spinal burst amplitude (Figs. 8C, 8D).

\subsection{Do spinal MOR receptors play a role during spinal OGD?}

Since naloxone preferentially blocks MOR, we further investigated the role of spinal MOR by applying specific MOR agonist and antagonist drugs to the spinal cord prior-to and during OGD. In one set of experiments $(n=8)$, DAMGO $(0.01 \mu \mathrm{M}$; MOR agonist) was spinally applied 10 min prior-to and during spinal OGD (see below for justification of DAMGO concentration). In one preparation, respiratory activity was abolished before the OGD onset; these data were excluded. In 7/8 preparations, DAMGO did not prolong cervical $(28.6 \pm 5.8 \mathrm{~min} ; \mathrm{p}=0.58)$ or thoracic $(32.2 \pm 7.2 \mathrm{~min} ; \mathrm{p}=0.29)$ endpoint times, respectively, compared to OGD only. In separate experiments $(n=7)$, we tested whether the combination of DOR activation and MOR blockade were additive. Accordingly, naltrexol (10 $\mu \mathrm{M}$; selective MOR antagonist) was applied to the spinal cord $10 \mathrm{~min}$ before initiating a spinal DPDPE $(1.0 \mu \mathrm{M})$ and OGD experiment similar to that shown in Fig. 3B. The combination of naltrexol and DPDPE increased cervical and thoracic end-point times to 33.9 $\pm 3.3 \mathrm{~min}(\mathrm{p}=0.021)$ and $34.1 \pm 2.6(\mathrm{p}=0.005)$, respectively, compared to spinal OGD only. However, these end-point times were not different compared to DPDPE/OGD alone $(\mathrm{p}>0.19)$. Thus, the naloxone-induced increase in end-point times during spinal OGD did not appear to involve MOR.

\subsection{Time-dependent effects of spinal DOR and MOR activation on respiratory motor output}

The ideal drug will not alter respiratory motor output while protecting against spinal OGD. However, while testing the higher concentrations of DADLE or DAMGO on the spinal cord, there were unexpected changes in respiratory burst frequency, or large decreases in spinal burst amplitude. To characterize potential time-dependent changes, drugs were dissolved in control aCSF and applied to the spinal cord for 90 min (or at least 20 min after activity was abolished in some cases). For example, spinal DADLE $(10 \mu \mathrm{M})$ application abolished spontaneous respiratory motor output in $2 / 5$ preparations as stated above in section 3.2. After spinal application of DADLE $(1.0 \mu \mathrm{M} ; \mathrm{n}=4)$ for $90 \mathrm{~min}$, thoracic burst frequency was $94 \pm 3 \%$ of baseline (baseline $=4.4 \pm 0.6$ bursts $/ \mathrm{min} ; \mathrm{p}=0.46$ ), but cervical and thoracic burst amplitudes decreased to $39 \pm 13 \%$ and $34 \% \pm 10 \%$ of baseline, respectively $(\mathrm{p}<0.03$ for drug effect; data not shown). In contrast, when DPDPE $(1.0 \mu \mathrm{M} ; \mathrm{n}=4)$ was spinally applied for $90 \mathrm{~min}$, thoracic burst frequency was not altered at $80 \pm 7 \%$ of baseline (baseline $=4.8 \pm 0.3$ bursts $/ \mathrm{min} ; \mathrm{p}=0.36$ for drug effect), and amplitude was not altered at $74 \pm 6 \%$ (cervical; $\mathrm{p}=0.49$ for drug effect) and $96 \pm 12 \%$ ) of baseline (thoracic; $\mathrm{p}=0.90$ for drug effect; data not shown).

With respect to MOR, spinal application of DAMGO $(1.0 \mu \mathrm{M} ; \mathrm{n}=3)$ abolished cervical and thoracic respiratory motor output at $70.5 \pm 9.5$ and $70.7 \pm 6.3 \mathrm{~min}$, respectively. Likewise, spinal application of DAMGO $(0.1 \mu \mathrm{M} ; \mathrm{n}=3)$ abolished cervical and thoracic respiratory motor output at $83.4 \pm 14.1$ and $86.1 \pm 17.1 \mathrm{~min}$, respectively. At both concentrations, cervical and thoracic burst amplitudes were reduced by $39-71 \%$ after only 30 min of drug application ( $\mathrm{p}<0.004$ for drug effects; data not shown). Thus, DAMGO at 0.1 and $1.0 \mu \mathrm{M}$ could not be used in combination with spinal OGD. Spinal application of DAMGO (0.01 $\mu \mathrm{M} ; \mathrm{n}=4)$ abolished respiratory motor output before $90 \mathrm{~min}$ in only $2 / 4$ preparations, but cervical and thoracic burst amplitudes were reduced by $36 \pm 22 \%$ and $54 \pm 2 \%$, respectively, after 90 min ( $p<0.015$ for drug effects; data not shown). DAMGO $(0.01 \mu \mathrm{M})$ was used for the OGD experiments in section 3.7 because this concentration produced the least deleterious effects on respiratory motor output. 


\subsection{Discussion}

This is the first study to demonstrate that spinal DOR activation before, during, and after spinal OGD onset prolongs spontaneously produced respiratory spinal motor output in neonatal rats in vitro. Thus, spinal DOR activation appears to be a versatile mechanism for protecting spinal motor networks during spinal OGD. Our data also suggest that there are complex interactions between opioid and ischemic signaling cascades. Naloxone prolonged spinal motor output during OGD, but end-point times were not altered by spinal MOR activation or DOR activation/MOR blockade, suggesting that spinal MOR activation was not neuroprotective. In contrast, DOR activation (with DPDPE) appears to be a potent neuroprotectant that attenuates the deleterious effects of the ischemic signaling cascade at various time points relative to OGD onset.

\subsection{Inspiratory spinal motor output is decreased by spinal OGD}

The neonatal rat brainstem-spinal cord preparation produces the inspiratory phase of the respiratory rhythm for $>2 \mathrm{~h}$ in vitro, which allows quantification of spontaneous motor output from identified ventral spinal nerve roots (Wang et. al 1996; Duffin et. al 2003). Only the inspiratory phase was typically produced in this study because the pons was removed from our preparations (Smith et. al 2007). When control aCSF bathed the brainstem and spinal cord, the $\mathrm{PO}_{2}$ in the superfusate was $458 \pm 17 \mathrm{~mm} \mathrm{Hg} . \mathrm{PO}_{2}$ levels in superfused brainstem-spinal cord preparations decrease by $\sim 100 \mathrm{~mm} \mathrm{Hg} / 100 \mu \mathrm{m}$ starting at $200 \mu \mathrm{m}$ above the tissue surface due to unstirred layers of solution (Okada et al., 1993). Thus, respiratory rhythm generating neurons in the brainstem and spinal motoneurons were functioning under aerobic conditions during baseline recordings (Okada et al., 1993; Brockhaus et. al, 2003). When hypoxic OGD solution was applied to the spinal cord, $\mathrm{PO}_{2}$ levels in the spinal compartment rapidly decreased to $165 \pm 22 \mathrm{~mm} \mathrm{Hg}$ within $10 \mathrm{~min}$. This suggests that spinal motoneurons were likely severely hypoxic within $10 \mathrm{~min}$ of the switch to OGD solution since $\mathrm{PO}_{2}$ in brainstem-spinal cord preparations decrease in parallel with the bath $\mathrm{PO}_{2}$ (Brockhaus et al., 1993).

Motor function is rapidly impaired soon after OGD onset in experimental spinal cord ischemia models. In vivo spinal ischemia in swine causes paraplegia and severe paresis $24 \mathrm{~h}$ after a 30-min aortic artery clamp (Lee et. al, 2008). Similarly, in vitro neonatal rat (P6-7) sagittally-hemisected lumbar spinal cords exposed to aglycemic and ischemic solutions have depressed electrically-evoked ventral spinal root potentials within 30-35 min (Jha and Deshpande, 2003; Deshpande and Jha, 2004). Spontaneous respiratory spinal motor activity may be more sensitive to OGD than electrically-evoked potentials because only $2 / 17$ preparations exposed to OGD in our study remained rhythmically active after $30 \mathrm{~min}$. However, differences in bath size, flow rates, animal age, and tissue condition (i.e., hemisected versus intact cord) may account for the difference in OGD sensitivity in vitro.

\subsection{Sustained DOR activation attenuates OGD-induced neuronal dysfunction}

Sustained DOR activation before ischemia in vivo or OGD in vitro decreases neuronal damage and improves markers of normal neuronal function. For example, in vivo DOR agonist administration in adult rats 15-45 min before ischemia improves CA1 (Su et al., 2007; Charron et al., 2008) and CA3 neuronal survival (Iwata et al., 2007), increases DOR protein expression (Tian et al., 2008b), reduces brain infarct and neurological deficits (Tian et al., 2008b) as well as improves behavior and motor scores (Su et al., 2007; Charron et al., 2008). Similarly, several DADLE injections administered prior to middle cerebral artery occlusion in rats decreases infarct size and apoptosis (Borlongan et al., 2009). In cortical neuron cultures, sustained DOR activation at the onset of glutamate excitotoxicity or hypoxia preserves membrane integrity, reduces swelling in neuronal bodies, decreases soma 
vacuolation and neurite fragmentation, and reduces lactate dehydrogenase release 4-24 h after injury (Zhang et al., 2000; Zhang et al., 2002).

In central motor circuits, however, less is known about OGD sensitivity and DORdependent neuroprotection. Intrathecal SNC-80 (DOR agonist) administration in adult rats 9-11 min before spinal ischemia improves hindlimb function $48 \mathrm{~h}$ later (Horiuchi et al, 2004) and decreases white matter injury in the spinal cord (Horiuchi et al, 2008). In this study, spinal DOR activation prior-to and during spinal OGD increased end-point times by up to $94 \%$ (1.0 $\mu \mathrm{M}$ DPDPE, thoracic). The larger DOR-induced end-point times for thoracic motor output may be due to regional differences in DOR expression and intracellular signaling within the spinal cord. Nevertheless, this is the first study to quantify DORdependent preservation of spontaneous, continuously active, neonatal spinal motor function during OGD.

\subsection{DOR activation post-OGD onset attenuates OGD-induced neuronal dysfunction}

Ideally, neuroprotective agents would provide neuronal protection after the onset of brain ischemia because therapeutic treatment is often started after clinical signs are manifested. Few studies, however, have specifically tested whether DOR activation after ischemia or OGD onset protects neural networks. For example, DOR activation immediately after transient middle cerebral artery occlusion in adult rodents reduces neurological deficits and infarct volume (Govindaswami et al., 2008; Tian et al., 2008a). To our knowledge, this is the first study to demonstrate DOR-dependent preservation of motor network function after OGD onset in a neonatal mammalian spinal cord in vitro. After 15 min of spinal OGD, spinal DOR activation (with ongoing spinal OGD) increased end-point times by up to $80 \%$ (1.0 $\mu \mathrm{M}$ DADLE, thoracic). These studies suggest that DOR activation disrupts the deleterious ischemic signaling cascade at multiple steps even if after the cascade is initiated. Further studies will be required to identify the time when respiratory motor output is irreversibly abolished or impaired despite spinal DOR agonist application.

\subsection{Brief DOR activation before spinal OGD attenuates OGD-induced neuronal dysfunction}

Few experiments have tested whether a brief period of DOR activation is protective against a future ischemic or OGD event. Tan-67 (selective DOR agonist) administration to adult rats $24 \mathrm{~h}$ before permanent right middle cerebral artery occlusion decreases infarct size and improves neurologic functional outcome (Zhao et al., 2006a). Similarly, under in vitro conditions, Tan-67 application to organotypic hippocampal slices $24 \mathrm{~h}$ before a 35-min OGD exposure reduces neuronal death in CA1 neurons (Zhao et al., 2006a). In this study, spinal application of DOR agonists 25 min prior to spinal OGD prolonged end-point times by up to $72 \%$ (1.0 $\mu \mathrm{M}$ DPDPE, thoracic). Of the two DOR agonists, DPDPE was more effective at increasing respiratory burst frequency at this concentration (see Figs. 6B-D), but neither DPDPE nor DADLE provided neuroprotection with respect to burst amplitude. Thus, brief spinal DOR activation appeared to induce signaling mechanisms that preserved respiratory burst frequency, but not amplitude. One caveat is that it is not known whether the DOR agonist drugs remained within the spinal tissue during the 25-min washout period and were released slowly to continuously activate spinal DOR receptors. Future experiments would be required to rule out this potential caveat.

\subsection{Role of spinal opioid receptors during OGD}

In the literature, there was controversy as to whether neonatal rats even expressed DOR in the CNS. Although DOR expression changes rapidly during development (Beland and Fitzgerald, 2001; Kivell et al., 2004), DOR are expressed in the neonatal rat forebrain (Milligan et al., 1987; Szucs et al., 1990), brainstem (Kivell et al., 2004) and spinal cord (Attali et al., 1990). Within the spinal cord, functional DOR are expressed at P0 and have 
similar affinity for specific agonists as adults (Attali et al., 1990). In addition, our data strongly suggest that functional DOR are expressed in the neonatal rat spinal cord because DOR agonists prolong respiratory motor output during spinal OGD.

Although DOR activation can provide neuroprotection, the results of blocking endogenous DOR (or other opioid receptors) before and during OGD are controversial. For example, intraperitoneal injections of naltrindole (DOR antagonist) $30 \mathrm{~min}$ prior to forebrain ischemia increase hippocampal CA1 neuronal death (Iwata et al., 2007). Also, in cultured cortical neurons, naltrindole application increases lactate dehydrogenase release during normoxic and hypoxic conditions (Zhang et al., 2002) as well as increases sodium azide-induced mitochondrial respiratory chain injury (Zhu et al., 2009). These data are consistent with the hypothesis that endogenous DOR activation is neuroprotective. In contrast, naltrindole application to hippocampal slices prior to brief OGD exposure improves recovery of population spike amplitude (Ammon-Treiber et al., 2005). In this study, the DPDPEdependent increase in cervical and thoracic end-point times was blocked by naltrindole, which suggests that DPDPE acted via DOR activation. Since naltrindole alone did not alter the response to spinal OGD, it appears that endogenous spinal DOR activation does not contribute to neuroprotection in these preparations.

Surprisingly, naloxone (general opioid receptor antagonist) increased end-point times by $22 \%$ (cervical) and 34\% (thoracic) when bath-applied prior-to and during spinal OGD. Since naloxone blocks DOR and MOR, and DADLE can crossover to activate MOR (Goldstein and Naidu, 1986), we hypothesized that endogenous MOR activation was somehow involved in the response to spinal OGD. However, MOR activation alone with spinal OGD did not alter end-point times, and DOR activation/MOR blockade did not act additively (or synergistically) to increase end-point times. These data suggest that there are complex interactions between opioid signaling pathways and the ischemic cascade induced by spinal OGD. On the other hand, naloxone may have exerted a wide range of neuroprotective biological effects that were not related to blocking opioid receptors. For example, naloxone administration following ischemia suppresses cytokine/chemokine production and preserves neuronal proteins (Chen et al., 2001; Liao et al., 2003) as well as restores mitochondrial activities or energy metabolism (Chen et al., 2000). Thus, spinal MOR activation or blockade may play only a minimal role in spinal neuroprotection.

\subsection{Potential mechanisms of DOR-dependent protection against OGD}

Reduced blood flow to the brain impairs $\mathrm{O}_{2}$ and glucose delivery, and initiates a cascade of events that eventually causes cell death (Pugliese et al., 2003; Bickler, 2004). The inability to generate ATP causes neuronal depolarization, deterioration of $\mathrm{Na}^{+}$and $\mathrm{K}^{+}$ion homeostasis, and excessive release of excitatory neurotransmitters. AMPA and NMDA receptor activation increases $\mathrm{Na}^{+}$and $\mathrm{Ca}^{2+}$ ion influx, which produces further neuronal depolarization, and leads to free radical production. Acute excitotoxicity leads to edema, neuronal damage, and cell death.

Activating endogenous central DOR is an attractive strategy for providing neuroprotection because DOR activation disrupts acute excitotoxic events and signaling pathways at multiple points to preserve ionic homeostasis and cell membrane integrity. For example, DOR activation inhibits excitotoxic influx of $\mathrm{Na}^{+}$ions via voltage-gated $\mathrm{Na}^{+}$channels (Chao et al., 2008, 2009) and attenuates OGD-induced increases in extracellular $\mathrm{K}^{+}$(Chao et al., 2007a,b). DOR activation also acts presynaptically to prevent glutamate release (Ostermeier et al., 2000) and postsynaptically to attenuate $\mathrm{Na}^{+}$ion influx via NMDA receptors (Chao et al., 2009). The intracellular signaling pathways for DOR-dependent neuroprotection are not well established. However, in embryonic cortical neuron cultures, DOR activation causes mitogen-activated protein kinase (MAPK) to phosphorylate extracellular signaling-regulated 
kinase (ERK) and prevent OGD-induced p38 phosphorylation, suggesting that the protective effects of DOR activation may be due to the balance of ERK and p38 activation (Sun et al., 2009). Taken together, these DOR-dependent mechanisms disrupt acute excitotoxicity at multiple points, and ultimately attenuate the cytotoxic rise in intracellular $\left[\mathrm{Ca}^{2+}\right](\mathrm{Chao}$ et al., 2010).

In this study, detailed mechanisms related to DOR activation were not addressed and beyond the scope of the present work. However, we hypothesize that prolongation of spinal respiratory motor output was primarily due to DOR-dependent attenuation of the early stages of OGD-induced excitotoxicity, such as those described above. DOR-dependent neuroprotection had to be fast-acting because spinal DOR activation prolonged respiratory motor output even $15 \mathrm{~min}$ after the onset of spinal OGD. Further studies will be required to test whether DOR-dependent mechanisms of neuroprotection first described in cortical neurons or cell cultures apply to the neonatal spinal cord.

\subsection{Clinical significance of DOR-dependent neuroprotection}

Due to the unpredictability of perinatal ischemic events, candidate neuroprotective agents must rapidly cross the blood-brain and placental barriers, provide long-lasting protection when administered before, during, or after ischemia, and have minimal adverse side effects (Johnson and Turner, 2010). To minimize potential clinically adverse effects, we used peptidergic drugs because some non-peptidergic DOR agonists, such as SNC-80, have been linked to convulsions in rats (Broom et al., 2002b; Jutkiewicz et al., 2005), mice (Comer et al., 1993; Broom et al., 2002a), and nonhuman primates (Dykstra et al., 1993; Negus et al., 1994; Pakarinen et al., 1995). Peptidergic DOR agonists may also cause EEG changes, but do not produce overt convulsions (Haffmans and Dzoljic, 1983), and there are examples where DPDPE was used safely without causing convulsions (Torregrossa et al., 2006).

Since opioid-induced respiratory depression is a significant life-threatening side effect, it's important to consider whether selective central DOR activation causes respiratory depression in neonatal mammals. The literature regarding DOR-dependent respiratory depression in adult mammals is controversial, in part, because several studies used relatively non-specific DOR agonists (Shook et al., 1990). Also, studies differ considerably with respect to species, drug dosage, method (bolus vs. infusion) and route (intravenous vs. intracerebroventricular) of drug administration, and animal state (awake vs. anesthetized) (Shook et al., 1990; Johnson and Turner, 2010). However, in neonatal mammals, DOR activation does not appear to cause respiratory depression with the use of highly selective DOR agonists. For example, intraperitoneal DPDPE injections $(0.1 \mathrm{mg} / \mathrm{kg})$ do not alter respiratory output in intact neonatal P1 rats (Greer et al., 1995). Also, bath-applied DPDPE does not alter spinal respiratory motor output or bulbospinal respiratory neuronal discharge in neonatal rat brainstem-spinal cord preparations (Greer, 1995; Takita et al. 1997; Takeda et al., 2001). In this study, respiratory motor output was not altered by spinal application of DPDPE for $>90 \mathrm{~min}$. Thus, it is possible that DOR agonist drugs may be safely used to treat perinatal ischemia in a wide variety of clinical conditions. In contrast, spinal MOR activation at even very low concentrations reduced spinal respiratory burst amplitude in isolated neonatal rat spinal cords. Therefore, MOR agonist drugs are not good candidates to provide clinically effective neuroprotection against ischemia.

\subsection{Conclusions}

Taken together, our data suggest spinal DOR activation can attenuate or delay the deleterious effects caused by OGD in the neonatal spinal cord. Also, this study shows that DOR activation can protect respiratory spinal motor networks, which are necessary for life. Thus, selective DOR agonist drugs may be ideal for neuroprotection because DOR 
activation does not cause respiratory depression and provides neuroprotection with great flexibility with respect to the timing of drug administration relative to the ischemic event.

\section{Acknowledgments}

This work was supported by the National Institute of Neurological Disorders and Stroke (NS-051580). S.M.F. Turner was supported by a National Heart Lung Blood Institute grant (T32 HL07654) and an American Physiological Society Undergraduate Summer Research Program. The authors also acknowledge Megan Gussick for her contributions to early pilot studies for this project.

\section{References}

Ammon-Treiber S, Stolze D, Schroder H, Loh H, Hollt V. Effects of opioid antagonists and morphime in a hippocampal hypoxia/hypoglycemia model. Neuropharmacology. 2005; 49:1160-1169. [PubMed: 16098996]

Attali B, Saya D, Vogel Z. Pre- and postnatal development of opiate receptor subtypes in rat spinal cord. Brain Res Dev Brain Res. 1990; 53:97-102.

Badr LK, Purdy I. Brain injury in the infant: The old, the new and the uncertain. J Perinat Neonat Nurs. 2006; 20:163-175.

Beland B, Fitzgerald M. Mu- and delta-opioid receptors are downregulated in the largest diameter primary sensory neurons during postnatal development in rats. Pain. 2001; 90:143-150. [PubMed: 11166980]

Bickler PE. Clinical Perspectives: neuroprotection lessons from hypoxia-tolerant organisms. J Exp Biol. 2004; 207:3243-3249. [PubMed: 15299045]

Borlongan CV, Hayashi T, Oeltgen PR, Su TP, Wang Y. Hibernation-like state induced by an opioid peptide protects against experimental stroke. BMC Biol. 2009; 7:31. [PubMed: 19534760]

Borlongan CV, Wang Y, Su TP. Delta opioid peptide [D-Ala2 D-Leu5] enkephalin: linking hibernation and neuroprotection. Frontiers in Biosci. 2004; 9:3392-3398.

Brockhaus J, Ballanyi K, Smith JC, Richter DW. Microenvironment of respiratory neurons in the in vitro brainstem-spinal cord of neonatal rats. J Physiol. 1993; 462:421-445. [PubMed: 8331589]

Broom DC, Nitsche JF, Pintar JE, Rice KC, Woods JH, Traynor JR. Comparison of receptor mechanisms and efficacy requirements for delta-agonist-induced convulsive activity and antinociception in mice. J Pharmacol Exp Ther. 2002a; 303:723-729. [PubMed: 12388657]

Broom DC, Jutkiewicz EM, Folk JE, Traynor JR, Rice KC, Woods JH. Convulsant activity of a nonpeptidic delta-opioid receptor agonist is not required for its antidepressant-like effects in SpragueDawley rats. Psychopharmacology 2002. 2002b; 164:42-48.

Chao D, Xia Y. Ionic storm in hypoxic/ischemic stress: Can opioid receptors subside it? Prog Neurobiol. 2010; 90:439-470. [PubMed: 20036308]

Chao D, Balboni D, Lazarus LH, Salvadori S, Xia Y. Na+ mechanism of $\delta$-opioid receptor induced protection from anoxic $\mathrm{K}^{+}$leakage in the cortex. Cell Mol Life Sci. 2009; 66:1105-1115. [PubMed: 19189047]

Chao D, Bazzy-Asaad A, Balboni G, Salvadori S, Xia Y. Activation of DOR attenuates anoxic K+ derangement via inhibition of $\mathrm{Na}+$ entry in mouse cortex. Cereb Cortex. 2008; 18:2217-2227. [PubMed: 18203692]

Chao D, Bazzy-Asaad A, Balboni G, Xia Y. $\delta$ - but not $\mu$-opioid receptor stabilizes $\mathrm{K}^{+}$homeostasis by reducing $\mathrm{Ca}^{2+}$ influx in the cortex during acute hypoxia. J Cell Physiol. 2007a; 212:60-67. [PubMed: 17373650]

Chao D, Donnelly D, Feng Y, Bazzy-Asaad A, Xia Y. Cortical $\delta$-opioid receptors potentiate $\mathrm{K}^{+}$ homestasis during anoxia and oxygen-glucose deprivation. J Cereb Blood Flow Metab. 2007b; 27:356-368. [PubMed: 16773140]

Charron C, Messier C, Plamondon H. Neuroprotection and functional recovery conferred by administration of kappa- and delta1-opioid agonists in a rat model of global ischemia. Physiol Behav. 2008; 93:502-511. [PubMed: 18031772] 
Chen CJ, Cheng FC, Liao SL, Chen WY, Lin NN, Kuo JS. Effects of naloxone on lactate, pyruvate metabolism and antioxidant activity in rat cerebral ischemia/reperfusion. Neurosci Lett. 2000; 287:113-116. [PubMed: 10854725]

Chen CJ, Liao SL, Chen WY, Hong JS, Kuo JS. Cerebral ischemia/reperfusion injury in rat brain: effects of naloxone. Neuroreport. 2001; 12:1245-1249. [PubMed: 11338200]

Comer SD, Hoenicke EM, Sable AI, McNutt RW, Chang KJ, De Costa BR, Mosberg HI, Woods JH. Convulsive effects of systemic administration of the delta opioid agonist BW373U86 in mice. J Pharmacol Exp Ther. 1993; 267:888-895. [PubMed: 8246164]

Deshpande SB, Jha A. Aglycemia and ischemia depress monosynaptic and polysynaptic reflexes in neonatal rat spinal cord in vitro by involving different types of 5-hydroxytryptamine receptors. Neurosci Lett. 2004; 372:167-172. [PubMed: 15531110]

Drew KL, Rice ME, Kuhn TB, Smith MA. Neuroprotective adaptations in hibernation: therapeutic implications for ischemia-reperfusion, traumatic brain injury and neurodegenerative diseases. Free Radic Biol Med. 2001; 31:563-573. [PubMed: 11522441]

Drew KL, Buck CL, Barnes BM, Christian SL, Rasley BT, Harris MB. Central nervous system regulation of mammalian hibernation: implications for metabolic suppression and ischemia tolerance. J Neurochem. 2007; 102:1713-1726. [PubMed: 17555547]

Duffin J. A commentary on eupnoea and gasping. Respir Physiol Neurobiol. 2003; 139:105-111. [PubMed: 14637317]

Dykstra LA, Schoenbaum GM, Yarbrough J, McNutt R, Chang KJ. A novel delta opioid agonist, BW373U86, in squirrel monkeys responding under a schedule of shock titration. J Pharmacol Exp Ther. 1993; 267:875-882. [PubMed: 8246162]

Freiberg SM, Gussick ME, Johnson SM. Delta-opioid receptor (DOR), protects spinal respiratory motor output in vitro. The FASEB Journal \#856. 2008a

Freiberg SM, Johnson SM. Delta-opioid receptor (DOR) activation provides neuroprotection against oxygen-glucose deprivation (OGD) in neonatal spinal respiratory motor circuits in vitro. Soc Neurosci Abst \#152.2. 2008b

Goldstein A, Naidu A. Multiple Opioid Receptors: Ligand selectivity profiles and binding site signatures. Mole Pharamacol. 1989; 36:265-272.

Govindaswammi M, Brown SA, Yu J, Zhu H, Bishop PD, Kindy MS, Oeltgen PR. Delta 2-specific opioid receptor agonist and hibernating woodchuck plasma fraction provide ischemic neuroprotection. Acad Emerg Med. 2008; 15:250-257. [PubMed: 18304055]

Greer JJ, Carter JE, al-Zubaidy Z. Opioid depression of respiration in neonatal rats. J Physiol. 1995; 485:845-855. [PubMed: 7562622]

Haffmans J, Dzoljic MR. Differential epileptogenic potentials of selective mu and delta opiate receptor agonists. J Neural Transm. 1983; 57:1-11. [PubMed: 6619826]

Horiuchi T, Kawaguchi M, Kurita N, Inous S, Sakamoto T, Nakamura M, Konishi N, Furuya H. Effects of delta-opioid agonist SNC80 on white matter injury following spinal cord ischemia in normothermic and mildly hypothermic rats. J Anesth. 2008; 22:32-37. [PubMed: 18306011]

Horiuchi T, Kawaguchi M, Sakamoto T, Kurita N, Inoue S, Nakamura M, Konishi N, Furuya H. The effects of the delta-opioid agonist SNC80 on hind-limb motor function and neuronal injury after spinal cord ischemia in rats. Anesth Analg. 2004; 99:235-240. [PubMed: 15281536]

Hwang BH, Chang KJ, Severs WB. Increased delta, but not mu, opiate receptor binding in the medulla oblongata of Long-Evans rats following 5-day water deprivation. Brain Res. 1986; 371:345-349. [PubMed: 3008947]

Iwata M, Inoue S, Kawaguchi M, Nakamura M, Konishi N, Furuya H. Effects of delta-opioid receptor stimulation and inhibition on hippocampal survival in a rat model of forebrain ischaemia. Brit J Anaest. 2007; 99:538-546.

Jha A, Desphande SB. Aglycemia and ischemia depress spinal synaptic transmission via inhibitory systems involving NMDA receptors. Eur J Pharmacol. 2003; 481:189-196. [PubMed: 14642785]

Johnson SM, Turner SMF. Protecting motor networks during perinatal ischemia: the case for deltaopioid receptors. Ann NY Acad Sci. 2010; 1198:260-270. [PubMed: 20536941] 
Jutkiewicz EM, Rice KC, Traynor JR, Woods JH. Separation of the convulsions and antidepressantlike effects produced by the delta-opioid agonist SNC80 in rats. Psychopharmacology. 2005; 182:588-96. [PubMed: 16163520]

Kivell BM, Day DJ, McDonald FJ, Miller JH. Developmental expression of $\mu$ and $\delta$ opioid receptors in the rat brainstem: evidence for a postnatal switch in $\mu$ isoform expression. Dev Brain Res. 2004; 148:185-196. [PubMed: 14766196]

Lee JS, Hong JM, Kim YJ. Ischemic preconditioning to prevent lethal ischemic spinal cord injury in a swine model. J Invest Surg. 2008; 21:209-214. [PubMed: 18615318]

Liao SL, Chen WY, Raung SL, Chen CJ. Neuroprotection of naloxone against ischemic injury in rats: role of mu receptor antagonism. Neurosci Lett. 2003; 345:169-172. [PubMed: 12842283]

Milligan G, Streaty RA, Gierschik P, Spiegel AM, Klee WA. Development of opiate receptors and GTP-binding regulatory proteins in neonatal rat brain. J Bio Chem. 1987; 262:8626-8630. [PubMed: 3036816]

Negus SS, Butelman ER, Chang KJ, DeCosta B, Winger G, Woods JH. Behavioral effects of the systemically active delta opioid agonist BW373U86 in rhesus monkeys. J Pharmacol Exp Ther. 1994; 270:1025-1034. [PubMed: 7932149]

Nelson KB. Perinatal Ischemic Stroke. Stroke. 2007; 38:742-745. [PubMed: 17261729]

Okada Y, Muckenhoff K, Holtermann G, Acker H, Scheid P. Depth profiles of $\mathrm{pH}$ and $\mathrm{PO}_{2}$ in the isolated brainstem-spinal cord of the neonatal rat. Respir Physiol. 1993; 93:315-326. [PubMed: 8235130]

Ostermeier AM, Schlosser B, Schwender D, Sutor B. Activation of $\mu$ - and $\delta$ - opioid receptors causes presynaptic inhibition of glutamatergic excitation in neocortical neurons. Anesthesiology. 2000; 93:1053-1063. [PubMed: 11020761]

Pakarinen ED, Woods JH, Moerschbaecher JM. Repeated acquisition of behavioral chains in squirrel monkeys: comparisons of a mu, kappa and delta opioid agonist. J Pharmacol Exp Ther. 1995; 272:552-559. [PubMed: 7853168]

Pugliese AM, Latini S, Corradetti R, Pedata F. Brief, repeated, oxygen-glucose deprivation episodes protect neurotransmission from a longer ischemic episode in the in vitro hippocampus: role of adenosine receptors. Br J Pharmacol. 2003; 140:305-314. [PubMed: 12970092]

Rennie JM, Hagmann CF, Robertson NJ. Outcome after intrapartum hypoxic-ischemia at term. Semin in Fetal \& Neonatal Med. 2007; 12:398-407. [PubMed: 17825633]

Smith JC, Abdala AP, Koizumi H, Rybak IA, Paton JF. Spatial and functional architecture of the mammalian brainstem respiratory network: a hierarchy of three oscillatory mechanisms. $\mathrm{J}$ Neurophysiol. 2007; 98:3370-3387. [PubMed: 17913982]

Shook JE, Watkins WD, Camporesi EM. Differential roles of opioid receptors in respiration, respiratory disease, and opiate-induced respiratory depression. Am Rev Respir Dis. 1990; 142:895-909. [PubMed: 2171388]

Sotero de Menezes M, Shaw DWW. Hypoxic-ischemic brain injury in the newborn. eMedicine. 2006:1-39.

Su D, Wang Z, Zheng Y, Zhao Y, Wang X. Dose-dependent neuroprotection of delta opioid peptide [D-Ala2, D-Leu5] enkephalin in neuronal death and retarded behavior induced by forebrain ischemia in rats. Neurosci Lett. 2007; 423:113-117. [PubMed: 17689189]

Sun K, Su DS, Wang XR. Delta opioid agonist [D-Ala2, D-Leu5] enkephalin (DADLE) reduced oxygen-glucose deprivation caused neuronal injury through the MAPK pathway. Brain Res. 2009; 1292:100-106. [PubMed: 19619518]

Szucs M, Coscia CJ. Evidence for delta-opioid binding and GTP-regulatory proteins in 5-day-old rat brain membranes. J Neurochem. 1990; 54:1419-1425. [PubMed: 2156021]

Takeda S, Eriksson LI, Yamamoto Y, Joensen H, Onimaru H, Lindahl SG. Opioid action on respiratory neuron activity of the isolated respiratory network in newborn rats. Anesthesiology. 2001; 95:740-749. [PubMed: 11575549]

Takita K, Herlenius EA, Lindahl SG, Yamamoto Y. Actions of opioids on respiratory activity via activation of brainstem mu-, delta-, and kappa-receptors; an in-vitro study. Brain Res. 1997; 778:233-241. [PubMed: 9462896] 
Tian XS, Zhou F, Yang R, Xia Y, Wu GC, Guo JC. Electroacupuncture protects the brain against acute ischemia injury via up-regulation of delta-opioid receptors in rats. J Chin Integr Med. 2008a; 6:632-638.

Tian XS, Zhou F, Yang R, Xia Y, Wu GC, Guo JC. Effects of intracerbroventricular injection of $\delta$ opioid receptor agonist TAN-67 or antagonist naltrindole on acute cerebral ischemia in rats. Sheng Li Xue Bao. 2008b; 64:475-484.

Torregrossa MM, Jutkiewicz EM, Mosberg HI, Balboni G, Watson SJ, Woods JH. Peptidic delta opioid receptor agonists produce antidepressant-like effects in the forced swim test and regulate BDNF mRNA expression in rats. Brain Res. 2006; 1069:172-181. [PubMed: 16364263]

van Schie PEM, Becher JG, Dallmeijer AJ, Barkhof F, Weissenbruch MM, Vermeulen RJ. Motor outcome at the age of one after perinatal hypoxic-ischemic encephalopathy. Neuropediatrics. 2007; 38:71-77. [PubMed: 17712734]

Volpe JJ. Perinatal brain injury: from pathogenesis to neuroprotection. Ment Retard Dev Disabil Res Rev. 2001; 7:56-64. [PubMed: 11241883]

Wang W, Fung ML, Darnall RA, St John WM. Characterizations and comparisons of eupnoea and gasping in neonatal rats. J Physiol. 1996; 490:277-292. [PubMed: 8745295]

Xia Y, Haddad GG. Major difference in the expression of delta- and mu-opioid receptors between turtle and rat brain. J Comp Neurol. 2001; 436:202-210. [PubMed: 11438924]

Zhao P, Haung Y, Zuo Z. Opioid preconditioning induces opioid receptor-dependent delayed neuroprotection against ischemia in rats. J Neuropathol Exp Neurol. 2006a; 65:945-952. [PubMed: 17021399]

Zhao YM, Sun LN, Zhou HY, Wang XL. Voltage-dependent potassium channels are involved in glutamate-induced apoptosis of rat hippocampal neurons. Neurosci Lett. 2006b; 398:22-27. [PubMed: 16434141]

Zhang JH, Gibney GT, Zhao P, Xia Y. Neuroprotective role of delta-opioid receptors in cortical neurons. Am J Physiol Cell Physiol. 2002; 282:C1225-C1234. [PubMed: 11997236]

Zhang JH, Haddad GG, Xia Y. Delta-, but not mu- and kappa-, opioid receptor activation protects neocortical neurons from glutamate-induced excitotoxic injury. Brain Res. 2000; 885:143-153. [PubMed: 11102568]

Zhang JH, Qian H, Zhao P, Hong SS, Xia Y. Rapid hypoxia pre-conditioning protects cortical neurons from glutamate toxicity through $\delta$-opioid receptor. Stroke. 2006; 37:1094-1099. [PubMed: 16514101]

Zhu M, Li M, Tian X, Ou X, Zhu C, Guo J. Neuroprotective role of $\delta$-opioid receptors against mitochondrial respiratory chain injury. Brain Res. 2009; 1252:183-191. [PubMed: 19056363]

\section{Abbreviations}

$\begin{array}{ll}\text { aCSF } & \text { artificial cerebrospinal fluid } \\ \text { DADLE } & {[\text { D-Ala2, D-Leu5]-enkephalin acetate salt }} \\ \text { DAMGO } & {\left[\text { D-Ala }{ }^{2}, \mathrm{~N}-\mathrm{MePhe}^{4}, \text { Gly-ol]-enkephalin }\right.} \\ \text { DOR } & \text { delta opioid receptor } \\ \text { DPDPE } & {\left[\mathrm{D}-\mathrm{Pen}^{2,5}\right] \text {-Enkephalin hydrate }} \\ \text { MOR } & \text { mu opioid receptor } \\ \text { OGD } & \text { oxygen glucose deprivation }\end{array}$


Research Highlights

- Sustained spinal DOR activation prolongs respiratory spinal motor output during OGD

- Spinal DOR activation prolongs respiratory spinal motor output post-OGD onset

- Brief spinal DOR activation before OGD prolongs respiratory spinal motor output 
A

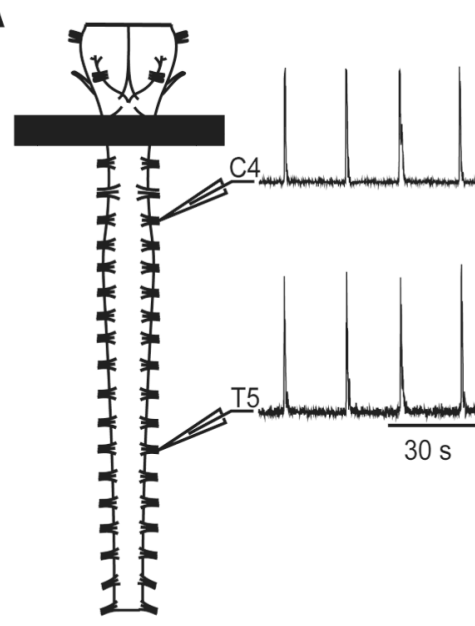

B
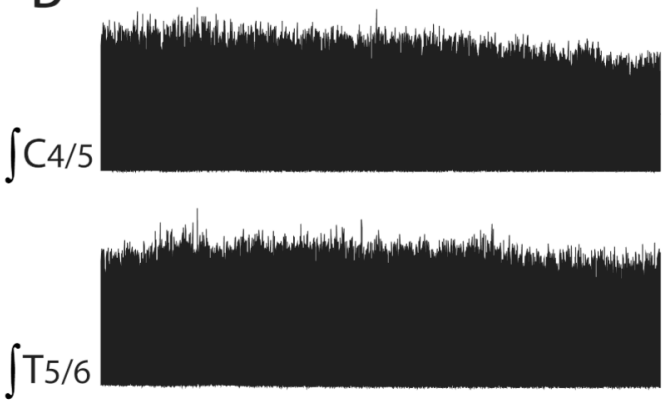

$20 \min$

Figure 1. Neonatal rat brainstem-spinal cord preparation produces spontaneous respiratory motor output

(A) Drawing of a brainstem-spinal cord split-bath preparation showing suction electrodes attached at ventral spinal roots at $\mathrm{C} 4$ and $\mathrm{T} 5$. Integrated and rectified spinal respiratory motor bursts are shown to the right of the suction electrodes. A plastic barrier at spinal segment $\mathrm{C} 1$ separates the brainstem compartment (upper) from the spinal cord compartment (lower). (B) Time-compressed records of spinal respiratory motor bursts are shown for a brainstem-spinal cord preparation bathed in aCSF for $120 \mathrm{~min}$. 

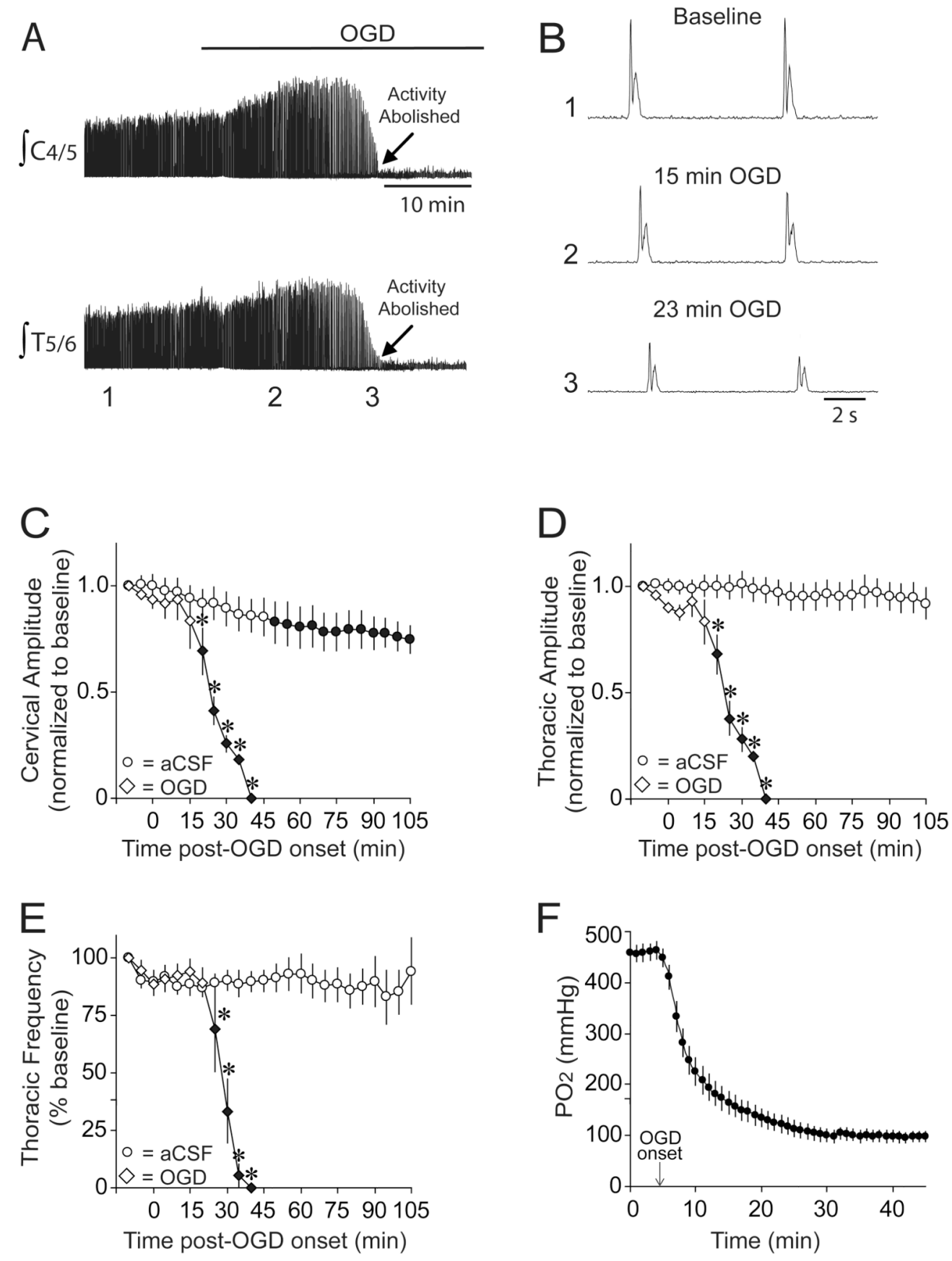

Figure 2. OGD decreases spinal respiratory burst amplitude and frequency

(A) Compressed records of integrated cervical (upper trace) and thoracic (lower trace) spinal respiratory motor output. Horizontal bar over the cervical traces indicates time when OGD solution was applied. Arrow and label shows when respiratory motor output was abolished. (B) Sample traces of thoracic motor output showing relatively little change in burst shape during OGD Traces 1, 2, and 3 were taken from the thoracic traces at the left in (A). (C-D) OGD (open diamonds) decreased cervical (C) and thoracic burst amplitude (D) compared to preparations exposed to aCSF for $120 \mathrm{~min}$ (open circles). (E) Normalized average thoracic burst frequency is shown for preparations exposed to aCSF for $120 \mathrm{~min}$ (open circles) or OGD (open diamonds). (F) Changes in spinal compartment $\mathrm{PO}_{2}$ are shown with spinal OGD 
onset starting at the 5-min time point. Filled symbols indicate significant time-dependent changes from baseline; asterisks indicate significant OGD-induced changes compared to aCSF time controls. 

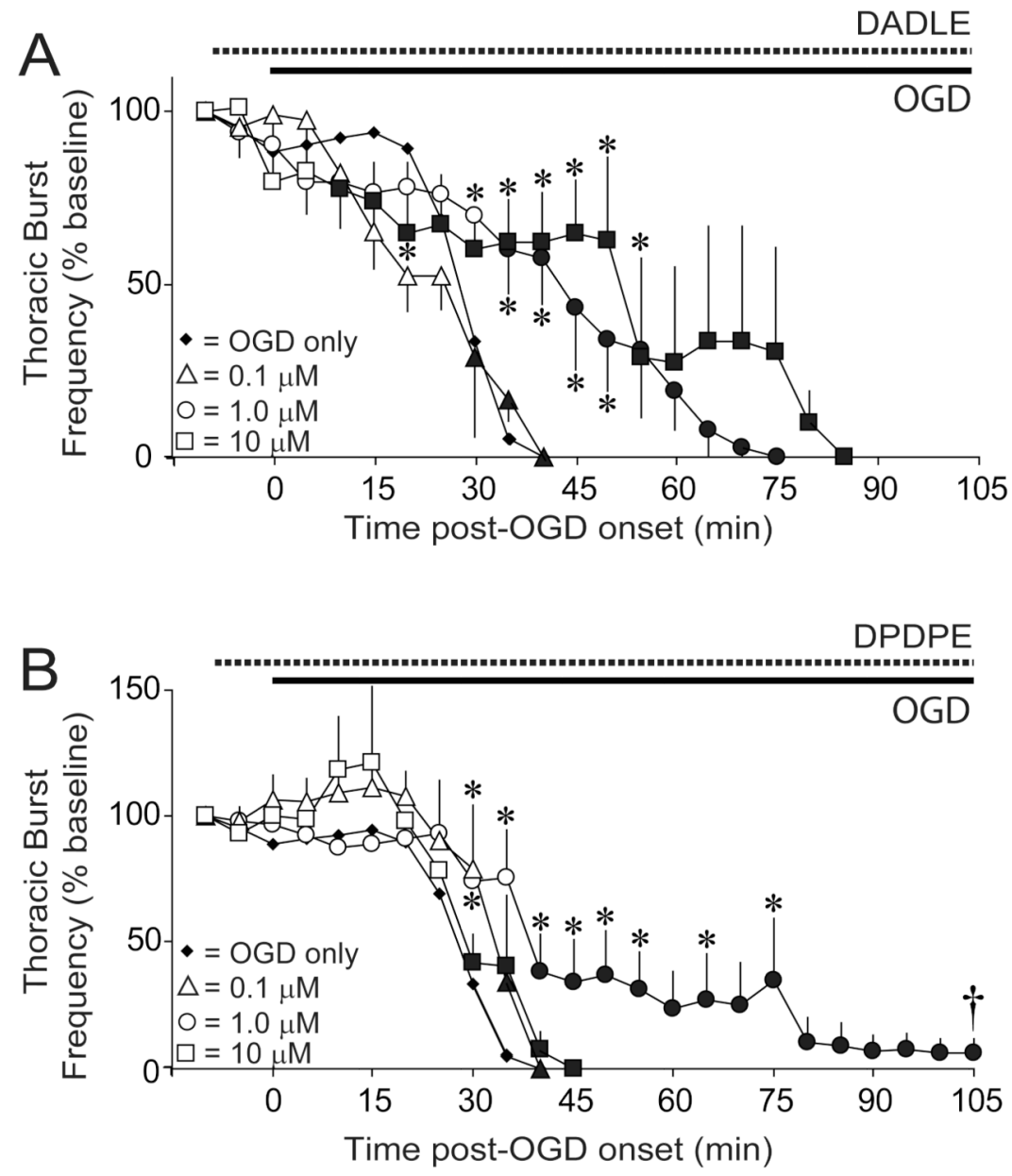

Figure 3. DOR activation prior-to and during spinal OGD prolongs respiratory spinal burst frequency

(A) Normalized thoracic burst frequency is shown for preparations exposed to spinal OGD alone (closed diamonds), or spinal OGD with either DADLE at $0.1 \mu \mathrm{M}$ (open triangles), 1.0 $\mu \mathrm{M}$ (open circles), or $10 \mu \mathrm{M}$ (open squares) applied prior-to and during OGD. Horizontal lines indicate timing of drug (dotted line) and OGD application (solid line). (B) Normalized thoracic burst frequency is shown for preparations exposed to spinal OGD alone (closed diamonds), or spinal OGD with either DPDPE at $0.1 \mu \mathrm{M}$ (open triangles), $1.0 \mu \mathrm{M}$ (open circles), or $10 \mu \mathrm{M}$ (open squares) applied prior-to and during OGD. Filled symbols indicate significant time-dependent changes from baseline; asterisks indicate significant OGDinduced changes compared to aCSF time controls; daggers indicate significant drug effect. 

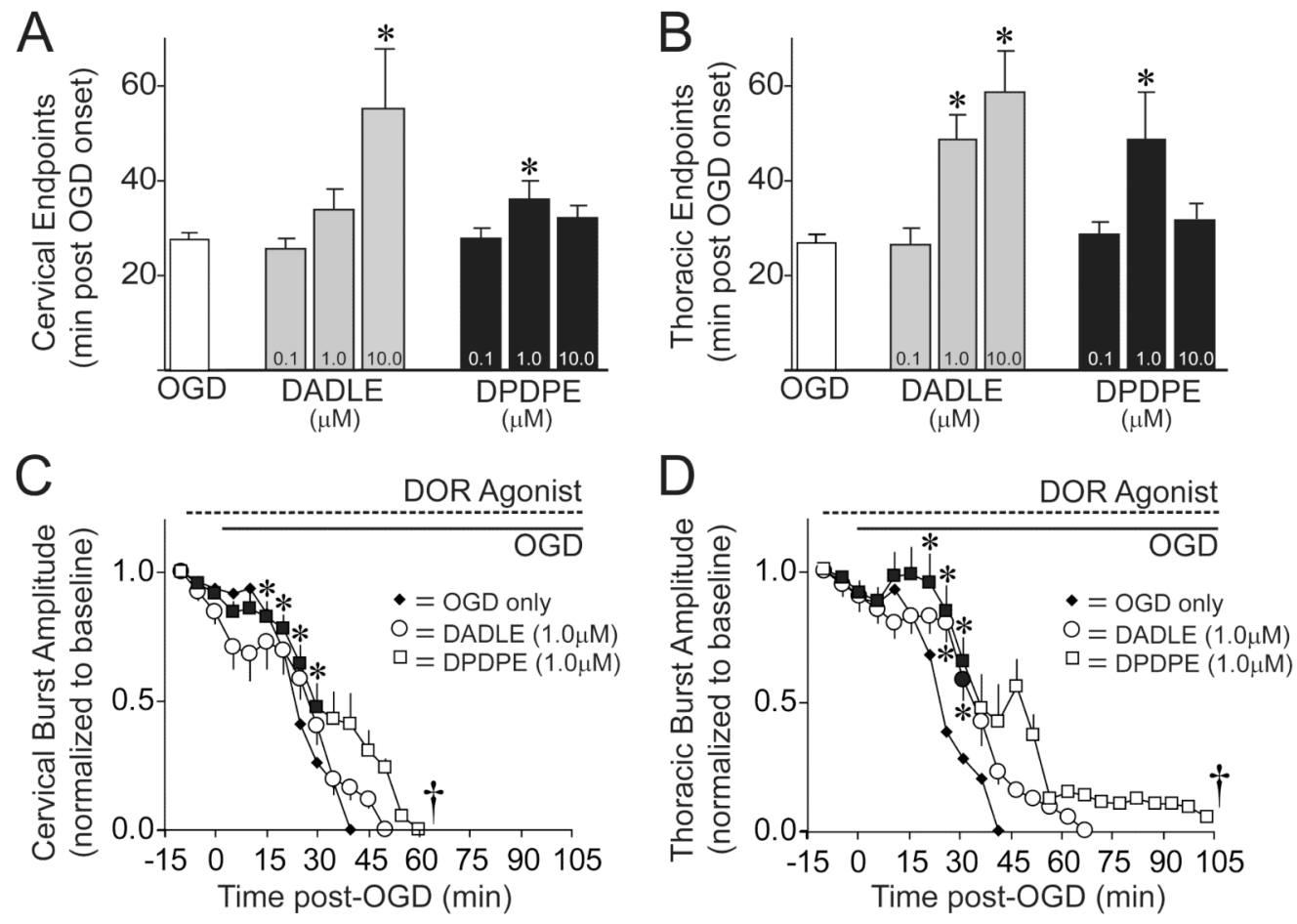

Figure 4. DOR activation prior-to and during spinal OGD increases end-point times and respiratory spinal burst amplitude

(A-B) End-point times (i.e., time from OGD onset to time when spinal nerve motor activity was abolished) were increased by spinal application of DADLE (gray bars) and DPDPE (black bars) for cervical (A) and thoracic (B) respiratory motor output compared to OGD (white bars). (C) DPDPE (1.0 $\mu \mathrm{M}$, open squares), but not DADLE (1.0 $\mu \mathrm{M}$, open circles), increased cervical respiratory burst amplitude during spinal OGD. Horizontal lines indicate timing of drug (dotted line) and OGD application (solid line). (D) DPDPE or DADLE increased thoracic respiratory burst amplitude during spinal OGD. Symbols are the same as those in Fig. 3. 
A

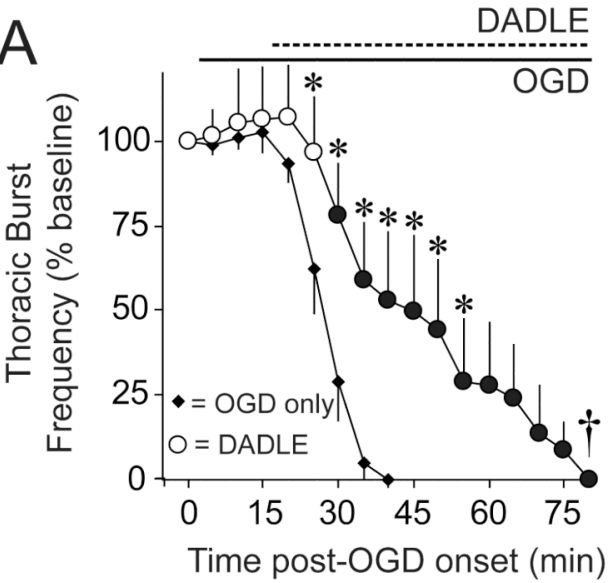

C

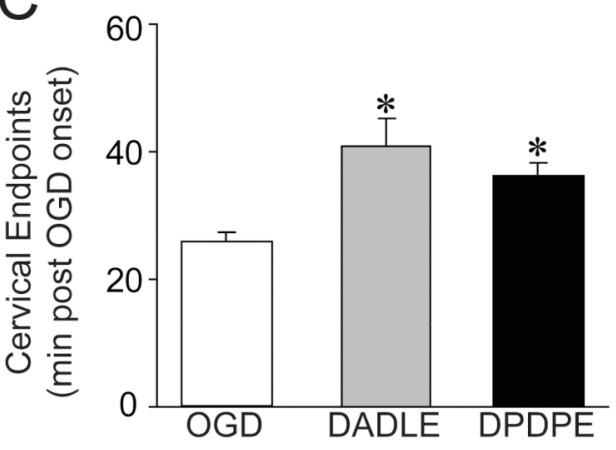

$E$

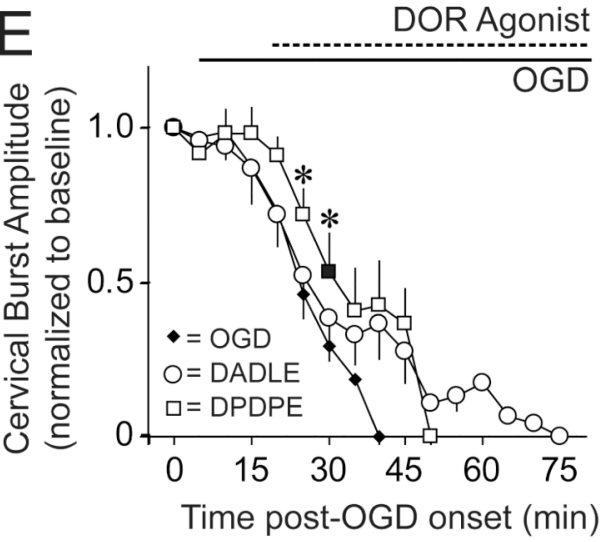

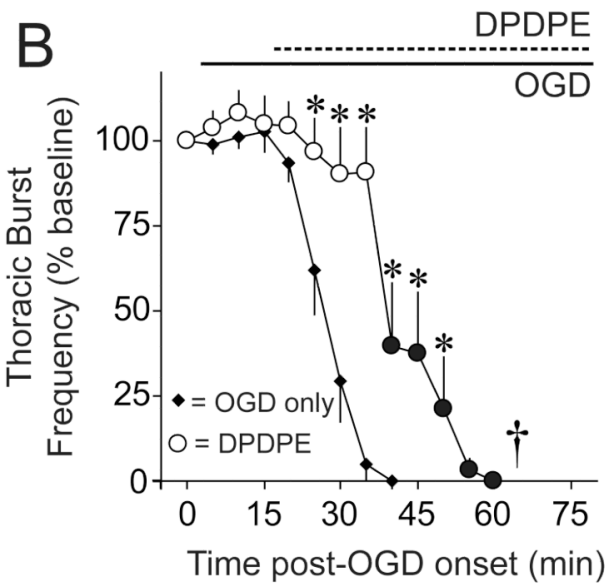
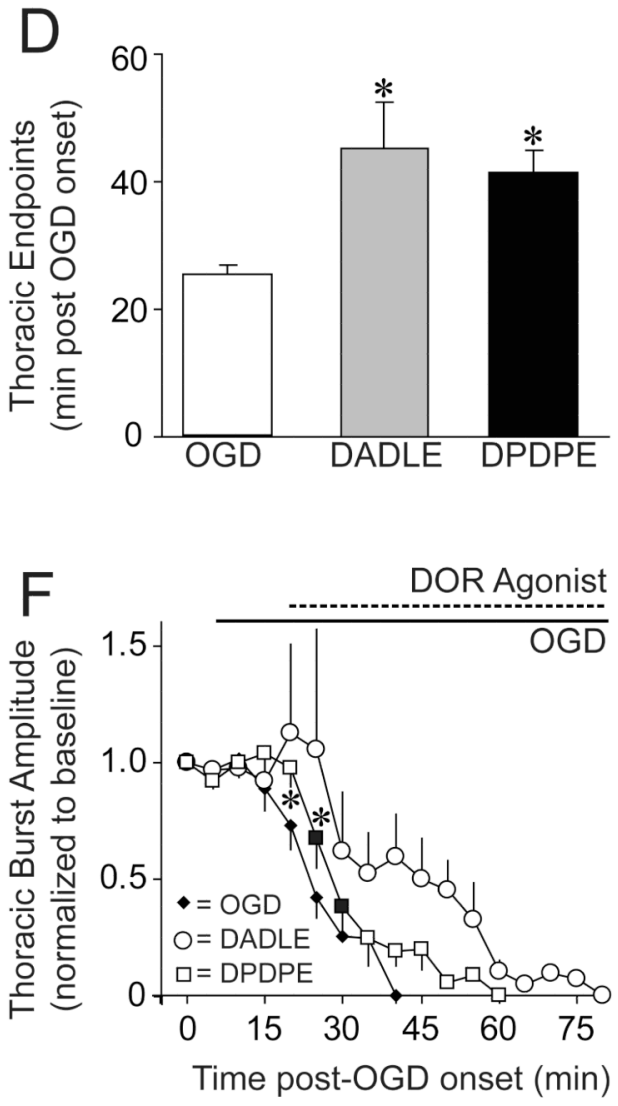

Figure 5. DOR activation post-OGD onset prevents OGD-induced decrease in respiratory burst frequency and amplitude

(A-B) Thoracic burst frequency was increased over time with 1.0 $\mu \mathrm{M}$ DADLE (A) or 1.0 $\mu \mathrm{M}$ DPDPE (B) (open circles) compared to OGD (closed diamonds) when the drugs were applied 15 min after spinal OGD onset. (C-D) End-point times were increased by DADLE (gray bars) and DPDPE (black bars) for cervical (C) and thoracic (D) respiratory motor output compared to OGD (white bars). (D-E) DPDPE (open squares), but not DADLE (open circles), increased burst amplitude at a few time points during spinal OGD for cervical (E) and thoracic $(F)$ respiratory motor output. Symbols are the same as those in Fig. 3. 


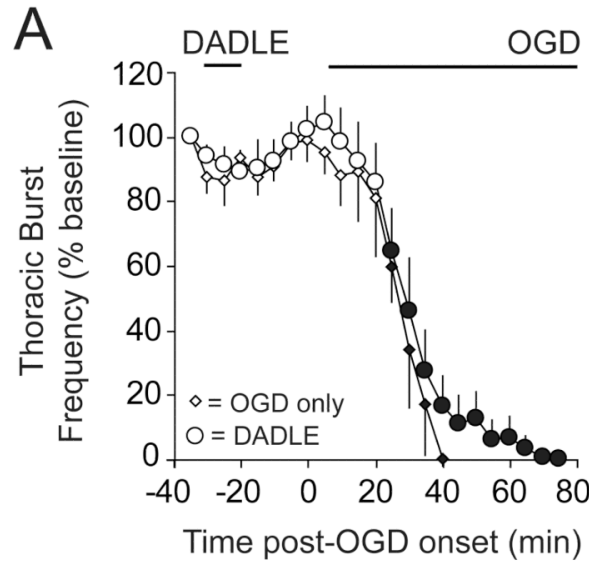

C

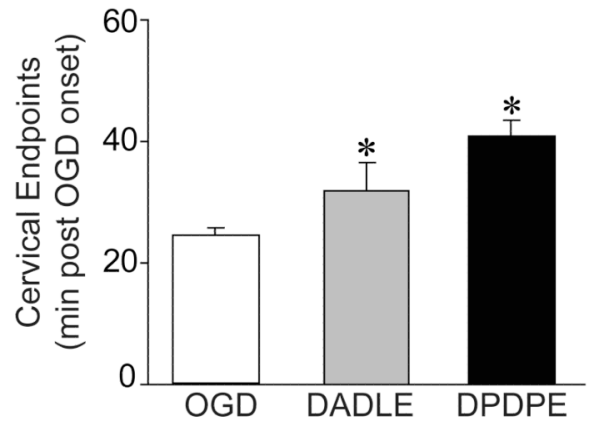

E
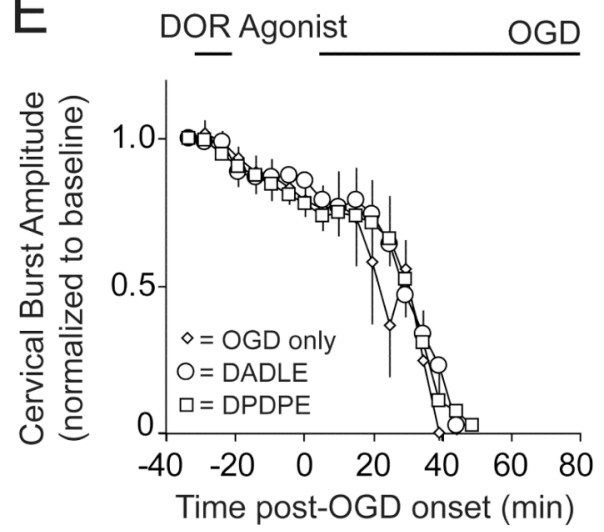

B

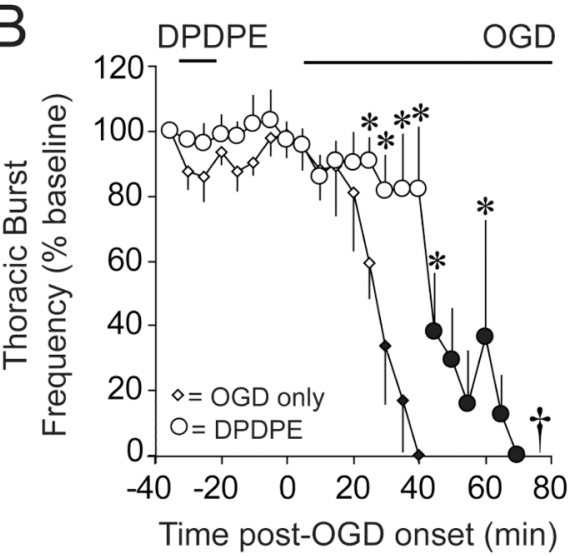

$\mathrm{D}$

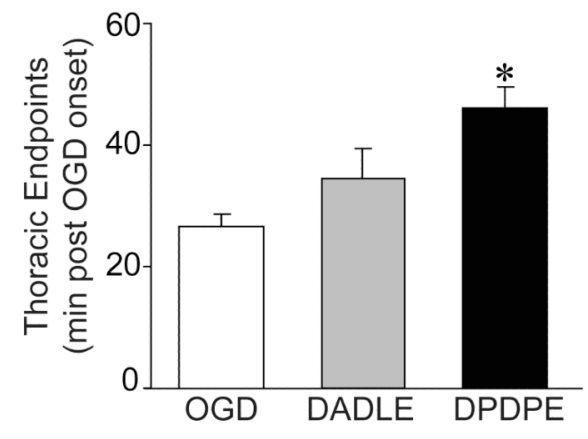

$\mathrm{F}$

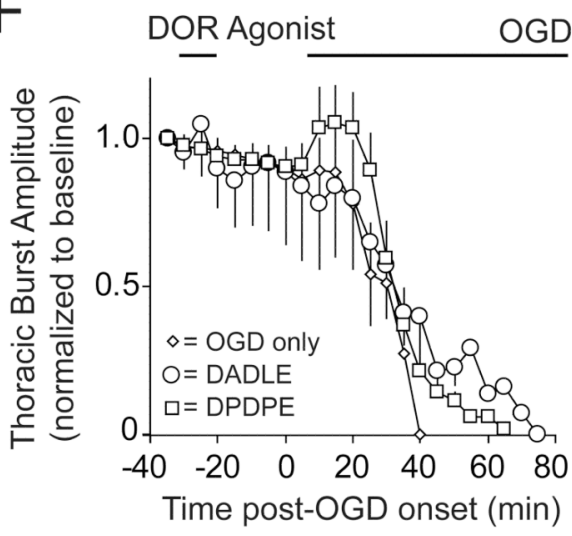

Figure 6. DOR activation $25 \mathrm{~min}$ before spinal OGD prevents OGD-induced decrease in respiratory burst frequency, but not amplitude

(A-B) Thoracic burst frequency was not changed with 1.0 $\mu \mathrm{M}$ DADLE (A), but increased with $1.0 \mu \mathrm{M}$ DPDPE (B) (open circles) compared to OGD (open diamonds). (C) End-point times were increased by DADLE (gray bar) and DPDPE (black bar) for cervical respiratory motor output compared to OGD (white bar). (D) End-point times were increased by DPDPE (black bar), but not DADLE (gray bar), for thoracic respiratory motor output compared to OGD (white bar). (E-F) DADLE (open circles) and DPDPE (open squares) did not alter cervical (E) or thoracic (F) respiratory burst amplitude compared to OGD (open diamonds). Symbols are the same as those in Fig. 3. 

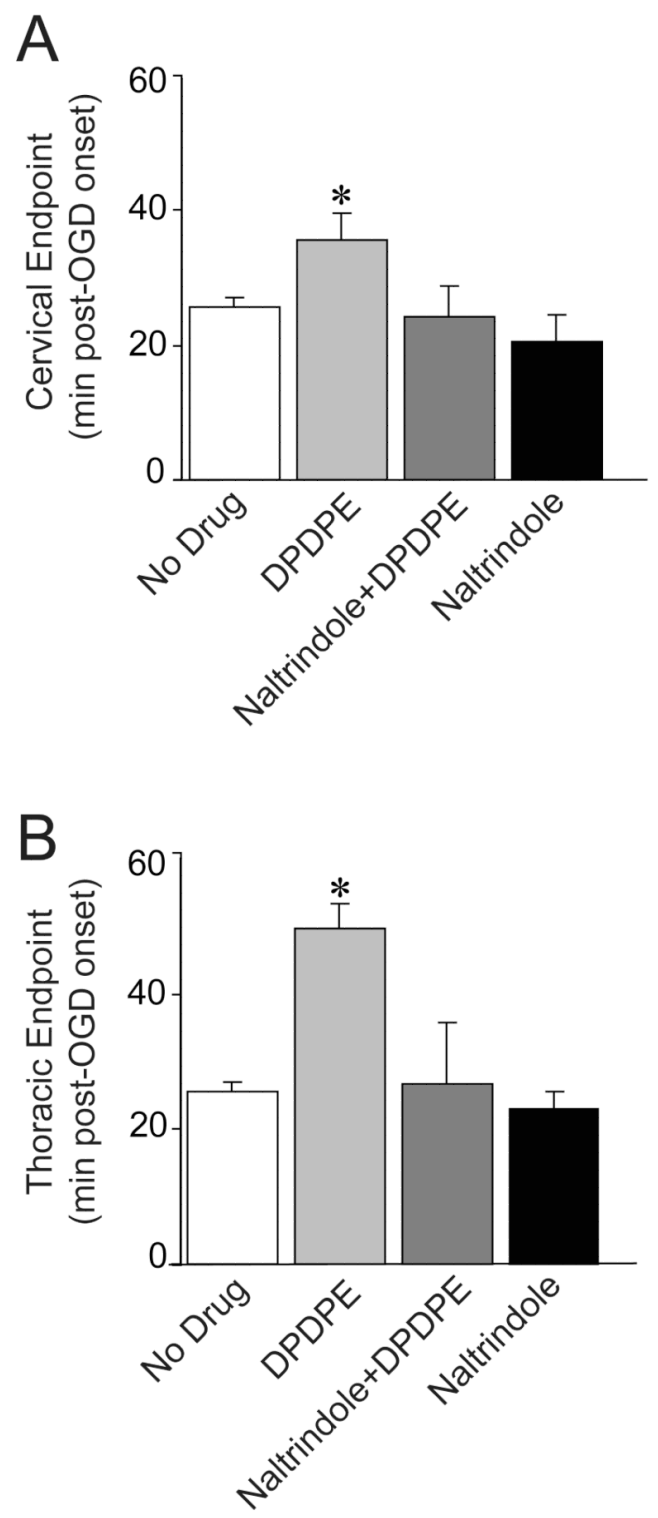

Figure 7. DOR antagonists block DPDPE-induced increase in end-point times (A-B) For cervical (A) and thoracic (B) respiratory motor output, end-point times for OGD only ("No Drug"; white bar) and 1.0 $\mu \mathrm{M}$ DPDPE application before and during OGD (light gray bar) are shown (data from Figs. 4A, 4B). Naltrindole (10 $\mu \mathrm{M})$ application before and during DPDPE/OGD application (dark gray bar) blocked DPDPE-dependent prolongation of end-point times. Naltrindole application before and during OGD (black bar) did not alter end-point times compared to OGD only. Asterisks indicate $\mathrm{p}<0.05$ compared to OGD. 
A

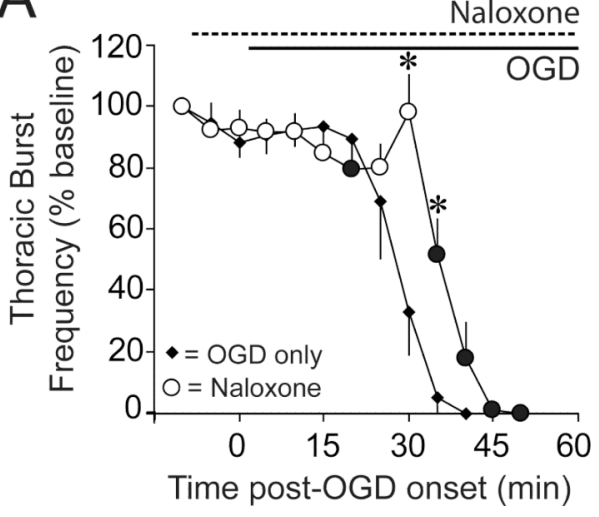

C

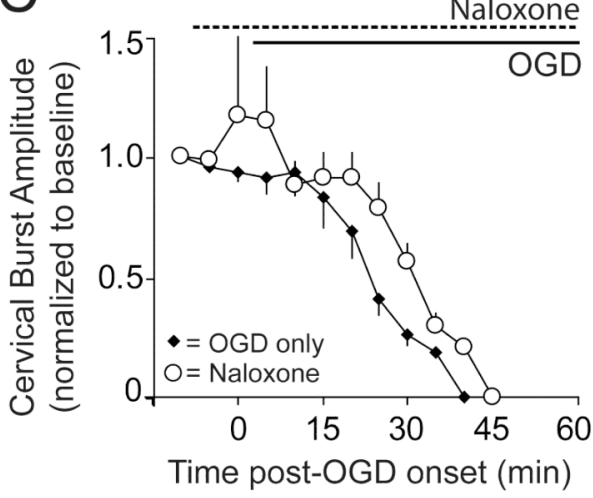

B

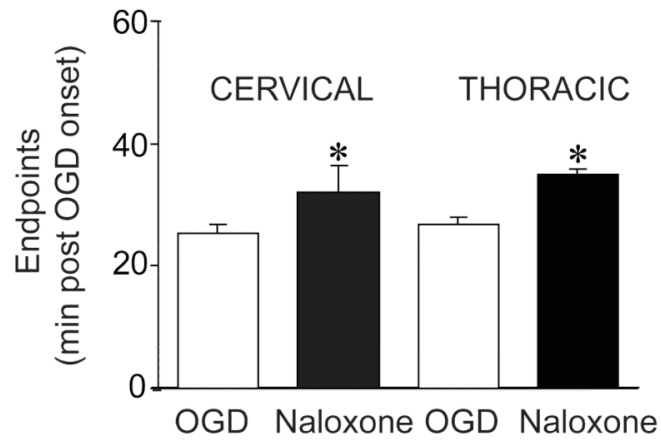

D

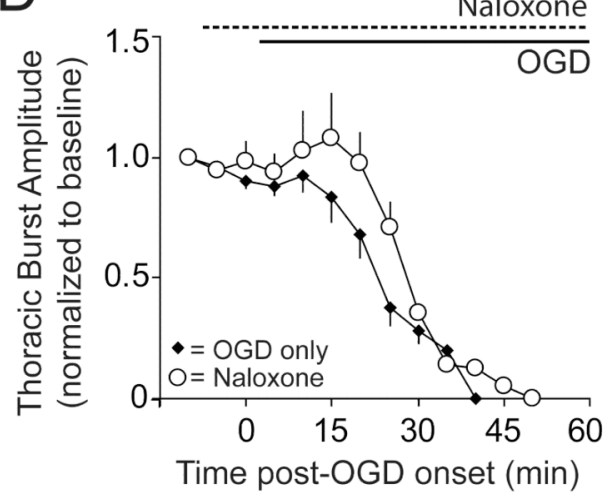

Fig. 8. Naloxone prolongs spinal respiratory output (A) Naloxone $(1.0 \mu \mathrm{M})$ applied spinally $10 \mathrm{~min}$ before and during spinal OGD (open circles) increased thoracic burst frequency at 30-35 min post-OGD onset (OGD data $=$ filled diamonds). (B) Cervical and thoracic end point times were increased by naloxone (black bars) compared to OGD (white bars); asterisks indicate $\mathrm{p}<0.05$ compared to OGD. (C, D) Naloxone (open circles) did not alter cervical (C) or thoracic (D) burst amplitude compared to OGD (filled diamonds). Symbols are the same as in Fig. 3. 